\title{
Identification and Characterization of Persistent Cold Pool Events from Temperature and Wind Profilers in the Columbia River Basin
}

\author{
KATHERINE MCCAFFREy, ${ }^{\mathrm{a}, \mathrm{b}, \mathrm{c}}$ JAMES M. WilCZAK, ${ }^{\mathrm{b}}$ LAURA BIANCO, ${ }^{\mathrm{b}, \mathrm{c}}$ ERIC Grimit, ${ }^{\mathrm{d}}$ \\ Justin SHARP, ${ }^{\mathrm{e}}$ Robert BANTA, ${ }^{\mathrm{f}}$ KATJA FrIEDRICH, ${ }^{\mathrm{g}}$ H. J. S. FERNANDO, ${ }^{\mathrm{h}}$ \\ RAGHAVENDRA KRISHNAMURTHY, ${ }^{\text {h,k }}$ LAURA S. LEO, ${ }^{\text {h,i }}$ AND \\ PAYTSAR MURADYAN ${ }^{j}$ \\ ${ }^{\text {a }}$ S\&P Global Market Intelligence, Boulder, Colorado \\ ${ }^{\mathrm{b}}$ Physical Sciences Division, NOAA/Earth System Research Laboratory, Boulder, Colorado \\ ${ }^{\mathrm{c}}$ CIRES, University of Colorado Boulder, Boulder, Colorado \\ ${ }^{\mathrm{d}}$ Vaisala, Seattle, Washington \\ e Sharply Focused, Portland, Oregon \\ ${ }^{\mathrm{f}}$ Chemical Sciences Division, NOAA/Earth System Research Laboratory, Boulder, Colorado \\ ${ }^{\mathrm{g}}$ Department of Atmospheric and Oceanic Sciences, University of Colorado Boulder, Boulder, Colorado \\ ${ }^{\mathrm{h}}$ University of Notre Dame, South Bend, Indiana \\ ${ }^{\mathrm{i}}$ Department of Physics and Astronomy, University of Bologna, Bologna, Italy \\ ${ }^{\mathrm{j}}$ Argonne National Laboratory, U.S. Department of Energy, Argonne, Illinois
}

(Manuscript received 20 February 2019, in final form 20 September 2019)

\begin{abstract}
Cold pool events occur when deep layers of stable, cold air remain trapped in a valley or basin for multiple days, without mixing out from daytime heating. With large impacts on air quality, freezing events, and especially on wind energy production, they are often poorly forecast by modern mesoscale numerical weather prediction (NWP) models. Understanding the characteristics of cold pools is, therefore, important to provide more accurate forecasts. This study analyzes cold pool characteristics with data collected during the Second Wind Forecast Improvement Project (WFIP2), which took place in the Columbia River basin and Gorge of Oregon and Washington from fall 2015 until spring 2017. A subset of the instrumentation included three microwave radiometer profilers, six radar wind profilers with radio acoustic sounding systems, and seven sodars, which together provided seven sites with collocated vertical profiles of temperature, humidity, wind speed, and wind direction. Using these collocated observations, we developed a set of criteria to determine if a cold pool was present based on stability, wind speed, direction, and temporal continuity, and then developed an automated algorithm based on these criteria to identify all cold pool events over the 18 months of the field project. Characteristics of these events are described, including statistics of the wind speed distributions and profiles, stability conditions, cold pool depths, and descent rates of the cold pool top. The goal of this study is a better understanding of these characteristics and their processes to ultimately lead to improved physical parameterizations in NWP models, and consequently improve forecasts of cold pool events in the study region as well at other locations that experiences similar events.
\end{abstract}

\section{Introduction}

Persistent cold-air pools commonly occur in many topographic basins during wintertime. This typically stagnant, cold-air layer in the lowest few hundred

\footnotetext{
${ }^{\mathrm{k}}$ Current affiliation: Pacific Northwest National Laboratories, Richland WA.
}

Corresponding author: Katherine McCaffrey, katherine.mccaffrey@ spglobal.com meters of the atmosphere can persist for several days, virtually cutting off near-surface processes from the overlying synoptic flow, until conditions align for the cold air to be removed (Wolyn and McKee 1989; Whiteman et al. 2001; Lareau et al. 2013). Persistent cold pools have been observed in many basins around the world including the Colorado plateau basin (Whiteman et al. 1999), the

Publisher's Note: This article was revised on 13 December 2019 to include the current affiliation for coauthor Krishnamurthy, which was omitted when originally published. 
Salt Lake basin (Lareau et al. 2013), the Gstettner-Alm sinkhole in Austria (Sauberer and Dirmhirn 1954), a Swiss valley (Vitasse et al. 2017), the eastern Pyrenees Mountains (Miró et al. 2018), and the Columbia River basin (Whiteman et al. 2001). Here, we focus on the persistent cold pools that remain (while synoptically forced upper layers modulate), rather than the diurnal nearsurface stable layers that get mixed out in the daytime.

The Second Wind Forecast Improvement Project (WFIP2) aimed to improve forecasting of atmospheric phenomena, including cold pools, with an extensive field-measurement campaign in the Columbia River basin. In this basin, cold pools initiate when low-level, easterly flow is blocked by the north-south-oriented Cascade Mountains, where the only outflow is through the narrow Columbia River Gorge, filling the basin with cold air. These flows therefore become stagnant, and with minimal surface heating, the layer remains stable while the flow aloft, which may become strong, often remains at the dominant westerly or southwesterly directions (Pichugina et al. 2019). As found in other locations, the episodes are often initiated by warming aloft via synoptic warm advection or subsidence, which isolate and trap the existing cold air in the basin (Wolyn and McKee 1989; Lareau et al. 2013). Radiational cooling at night and resulting drainage flows intensify the stability of the cold-air layer and help to maintain the cold-air pool through the episode, while broader synoptically forced conditions modulate above.

Under weak synoptic forcing, nighttime downslope orographic flow results in pooling of cold, dense air. Weak wintertime surface heating or persistent cloud cover inhibit daytime growth of the convective boundary layer and mix out of the nighttime stable layer. This can allow cold pools to remain for several days. Cold air trapped at the surface, often observed to have low wind speeds, creates a very stable atmosphere resulting in prolonged periods with poor air quality and low wind energy resources, and can lead to hazardous weather conditions such as fog and freezing rain (Wolyn and McKee 1989; Whiteman et al. 2001; Olofson et al. 2009; Whiteman et al. 2014; Chachere and Pu 2016; Chemel et al. 2016). Concerns over air quality during cold pool events have led to multiple field studies in areas of complex terrain, such as the Salt Lake City area (Lareau et al. 2013), where urban pollutants become trapped in the cold pools, reaching concentrations well over the National Ambient Air Quality Standard (Silcox et al. 2012).

Cold pool removal is often abrupt, so wind speeds can drastically ramp up. These wind ramps present a major challenge for integrating wind energy into the electrical grid, since the temporal variability must be quickly balanced by other resources (Francis 2008). Cold pools are terminated by different mechanisms, including the
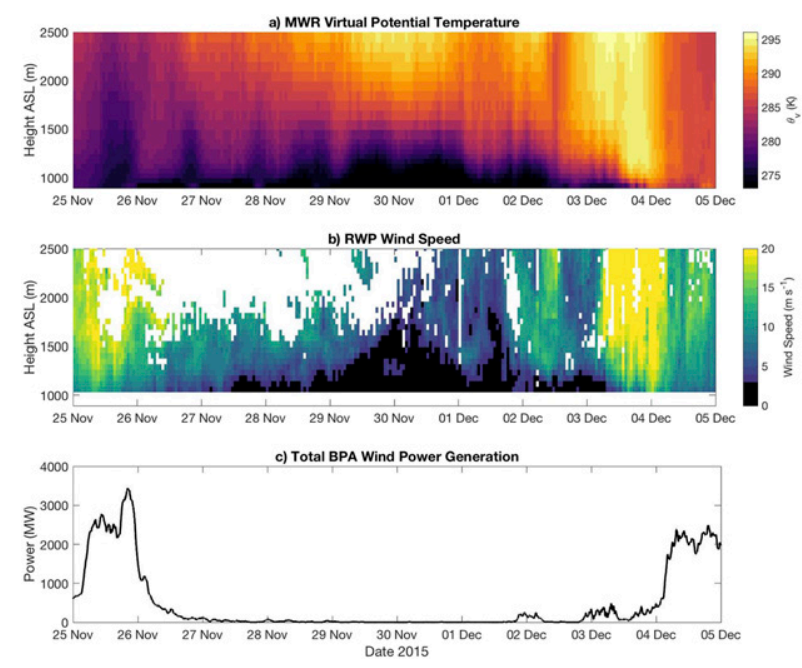

FIG. 1. An example of a multiday cold pool event in November and December 2015: (a) time-height cross section of virtual potential temperature from the MWR at Condon, OR; (b) timeheight cross section of wind speed from the $915-\mathrm{MHz}$ RWP at Condon, OR, with wind speeds below cut-in speed of $3 \mathrm{~m} \mathrm{~s}^{-1}$ in black; (c) time series of wind power generation in the Bonneville Power Administration's control region.

advection of cooler air aloft into the region, which reduces the stability at the top of the cold pool layer; displacement of the cold air out of the basin by strong winds aloft; turbulent erosion of the top of the cold pool by shear generated by strong winds aloft; and growth of the daytime convective boundary layer, formed by surface heating, upward through the cold pool. Large-amplitude lee waves, generated over barriers that are upstream with respect to the ridgetop winds, can also play a role in the dissipation of cold pools (Zhong et al. 2001; Whiteman et al. 2001). Often two or more of these mechanisms interact, for example, cold-air advection aloft may weaken the inversion at the top of the cold pool to such a degree that daytime heating can generate a strong enough CBL to mix out the cold pool.

After the cold pool has been removed, high wind speeds from aloft can mix down to the surface. This is a critical event in the Columbia River basin since the $4.6 \mathrm{GW}$ of installed capacity of wind turbines generates little to no power during cold pools, then ramps up when the cold pool departs (Bonneville Power Administration 2018). A sample time-height cross section of virtual potential temperature and wind speeds during a persistent cold pool event at Condon, Oregon, is shown in Fig. 1, along with the total wind power generation in the Bonneville Power Administration (BPA) region. For the duration of the cold pool event, the wind power generation is virtually zero, but as the warm air aloft descends, and the cold pool mixes out (3-4 December 2015), the wind speed quickly increases. 
Correctly representing the atmospheric boundary layer processes responsible for the strong increases (and decreases) in wind speed, which can reach $10-15 \mathrm{~m} \mathrm{~s}^{-1}$, is a major challenge for mesoscale weather prediction models (Greaves et al. 2009; Fernando and Weil 2010; Bossavy et al. 2013; Bianco et al. 2016).

Despite being a significant wintertime meteorological phenomenon in the Columbia River basin, the duration and mix out of cold pools remain a particularly difficult forecast challenge (Smith et al. 1997; Reeves and Stensrud 2009; Pagès et al. 2017). Numerical studies have analyzed many scales of processes that lead to the maintenance and mix out of cold pools (Vrhovec 1991; Petkovšek 1992; Zhong et al. 2001, 2003; Billings et al. 2006; Lareau and Horel 2015b; Grant and van den Heever 2016; Crosman and Horel 2017), yet operational forecasts continue to produce positive wind speed (and therefore, wind power generation) biases throughout the duration of the event, and often mix out the cold pool too early (Wilczak et al. 2019). These model errors, particularly due to the turbulence parameterizations used in stable layers, call for increased observations and model studies.

The importance of properly simulating cold pool properties by NWP models was demonstrated by Pichugina et al. (2019) using wind-profile data taken during WFIP2. They used annual and seasonal averages of wind data from three scanning Doppler lidars deployed to different sites to validate the National Oceanic and Atmospheric Administration (NOAA) High-Resolution Rapid Refresh (HRRR) NWP model. Validations against wintertime wind profiles from these lidars revealed a systematic overprediction of wind speeds at the highest site (Wasco). Pichugina et al. (2019) attributed these spuriously strong winds, which did not appear at the lower sites, to the model often underpredicting the depth of the cold pool, leaving the highest site exposed to the stronger winds aloft. Accurate simulation of wind speeds under cold pool conditions, important to wind energy, thus depends on properly predicting the depth of the weak-wind, cold pool layer, which in turn depends on accurate measurements of this quantity for validation. With many profiles of wind speed and temperature at multiple sites, WFIP2 provides this study with a unique dataset to characterize persistent cold pool events over 18 months with many profiling instruments, whereas most previous observational studies of cold pools have had far fewer instruments or have not spanned multiple winters.

The present analysis focuses on the development of criteria for the detection of cold pools and using the identified events to determine cold pool statistical characteristics. To take full advantage of the observational dataset to quantify cold pool features, cold pool must first be defined. This requires some a priori knowledge of the phenomenon, so we will begin with a basic definition based on stability, wind speed, and duration used previously (Whiteman et al. 2001), and modify it to take advantage of the vertical profiles available in WFIP2. Other characteristics of the cold pool, such as depth and descent rate of the top boundary, will also be defined based on case studies. Once the criteria for identifying cold pools are defined, the observations can then be used in an automated approach to identify all cold pool events throughout the WFIP2 field campaign, and the features and characteristics of the atmosphere during the events can be quantified through averages and distributions. Thus, the paper is organized as follows: section 2 introduces the WFIP2 field campaign, section 3 details one example cold pool event, section 4 defines the criteria necessary for identifying cold pools and defines some characteristics, section 5 uses the definitions in section 4 to automatically identify and statistically analyze all cold pool events and their features, and section 6 provides a summary and conclusion.

\section{The Second Wind Forecast Improvement Project}

WFIP2 took place in the Columbia River Gorge and basin in Oregon and Washington, where the complex terrain of the Cascade Mountains and Columbia River make local weather forecasts particularly difficult. The aim of the project was to improve understanding and modeling of physical phenomena in complex terrain, particularly those that impact winds at turbine heights. This understanding was then incorporated into operational numerical weather prediction models run at the NOAA (Olson et al. 2019). The focus was on day-ahead forecast lead times, and the participation by the BPA and wind farm operators in the project included an emphasis on developing decision support tools for grid operations. Five main meteorological phenomena were targeted by the extensive 18-month field campaign: mountain waves, convective outflows, gap flows including those forced by marine pushes/thermal troughs, cold pools, and topographic wakes. During WFIP2, a subjective expert meteorological evaluation of each day was documented in an event log that identified these 5 meteorological phenomena occurring in the region, including cold pools. Shaw et al. (2019) provides an overview of the project goals in more depth, and Wilczak et al. (2019) describes the field campaign strategy and instrumentation. Figure 2 shows a map of the field campaign region, with site/instrument locations providing observations used in the present study.

The Columbia River basin is actually a complex of basins and valleys. Whiteman et al. (2001) and Zhong et al. (2001) studied the cold-air pools in the Columbia 


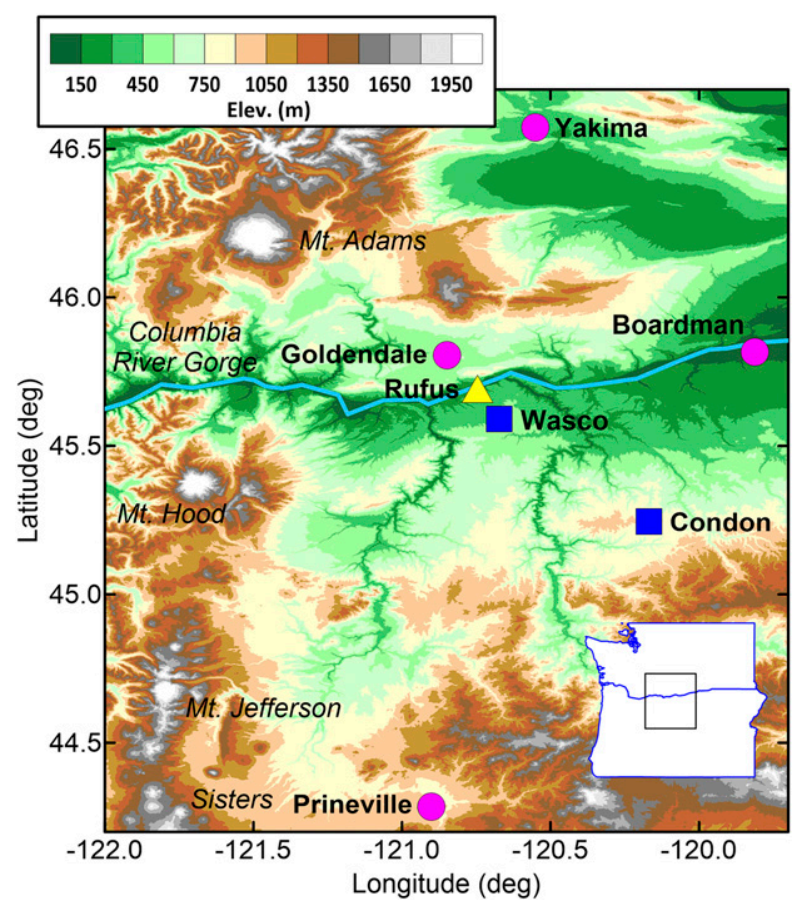

FIG. 2. Map of the WFIP2 study region shaded by elevation, with the relevant instrumentation to this study (seven sites with collocated instruments) identified as colored shapes, ordered by the most frequent combination to the least: blue squares are locations with RWP/RASS, MWR, and sodars; magenta circles have RWP/RASS and sodars; yellow triangle has MWR and sodar. Major geographical features are also labeled in italics.

basin, but their study was in a different portion of the basin, which Whiteman et al. (2001) refer to as the Pasco subbasin. The deep river-valley portion of the basin where WFIP2 took place is longer and narrower than the Pasco subbasin, but the two are connected and would experience the same cold pools.

A north-south transect was created by sites with collocated wind and temperature profiling instrumentation, with Yakima (YKM) and Goldendale (GDL) to the north of the Columbia River, Rufus (RFS) at river level, and Wasco (WCO), Condon (CDN), and Prineville (PVE) to the south. Boardman (BOR) is situated at river level [107 $\mathrm{m}$ above sea level (MSL)], $80 \mathrm{~km}$ east of RFS. The availability of wind and temperature measurements throughout the 18-month campaign at the seven sites of interest, as well as site elevations MSL, is shown in Fig. 3.

\section{a. Wind profilers: Radars and sodars}

During the WFIP2 field campaign, 19 sodars and 11 radar wind profilers (RWPs) were deployed. Of the seven sites that had collocated temperature profilers (see Table 1), six sites had both RWPs and sodars for a full profile of horizontal winds from near the surface to above $2 \mathrm{~km}$ above ground level (AGL), whereas one
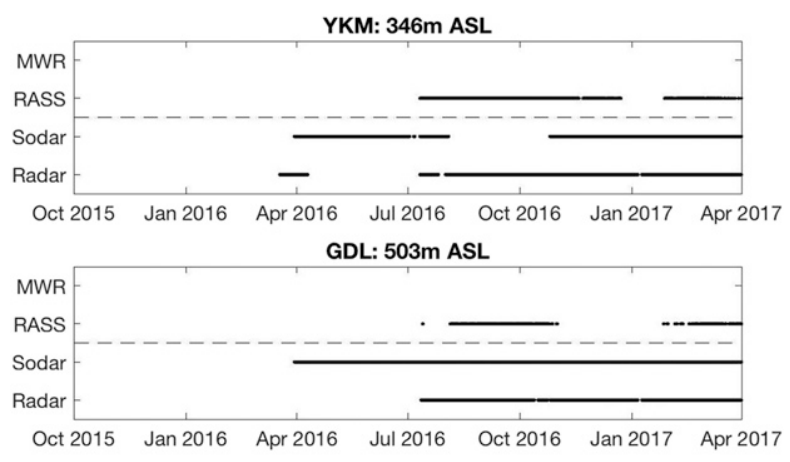

BOR: $107 \mathrm{~m}$ ASL
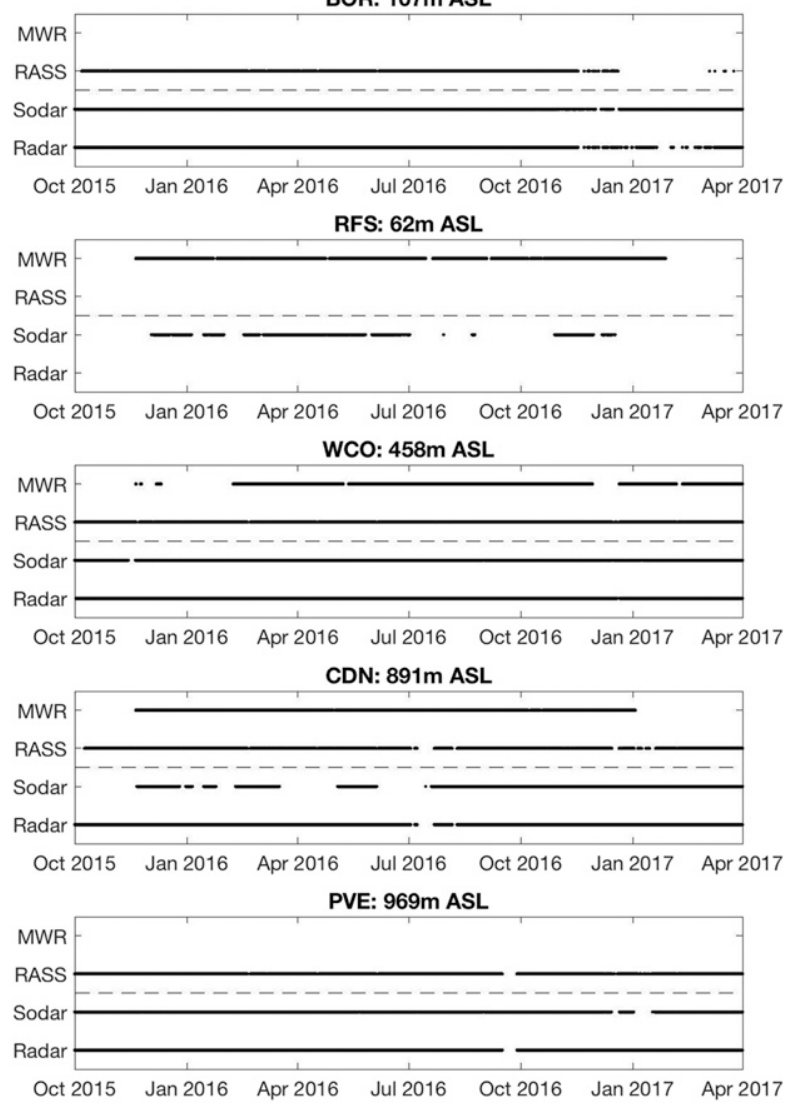

FIG. 3. Data availability throughout the field campaign at the seven sites with collocated temperature and wind speed measurements.

site (RFS) had only a sodar. The six $915-\mathrm{MHz}$ RWPs provided hourly averaged wind speeds at varying heights at each site, from the lowest measurement between 54 and $138 \mathrm{~m}$ to the highest measurement between 2280 and $2555 \mathrm{~m}$ AGL (we utilized the high resolution mode from the RWPs, which has $58 \mathrm{~m}$ vertical spacing, but a lower height range). Seven sodars observed from 10,15 , or $30 \mathrm{~m}$ AGL to 200,250 , or $400 \mathrm{~m}$ in 10 - or 15 -min intervals. These were combined into 60-min averages, and time stamped at the beginning of the hour, to match the RWP measurements. 
TABLE 1. List of locations with their site codes and elevations, and operating wind and temperature profiling instrumentation.

\begin{tabular}{|c|c|c|c|c|c|c|}
\hline Site & Site code & Elevation (m MSL) & RWP & Sodar & RASS & MWR \\
\hline Yakima, WA & YKM & 346 & $\mathrm{Y}$ & $\mathrm{Y}$ & $\mathrm{Y}$ & $\mathrm{N}$ \\
\hline Goldendale, WA & GDL & 503 & $\mathrm{Y}$ & $\mathrm{Y}$ & $\mathrm{Y}$ & $\mathrm{N}$ \\
\hline Boardman, OR & BOR & 107 & $\mathrm{Y}$ & $\mathrm{Y}$ & $\mathrm{Y}$ & $\mathrm{N}$ \\
\hline Rufus, OR & RFS & 62 & $\mathrm{~N}$ & $\mathrm{Y}$ & $\mathrm{N}$ & $\mathrm{Y}$ \\
\hline Wasco, OR & WCO & 458 & $\mathrm{Y}$ & $\mathrm{Y}$ & $\mathrm{Y}$ & $\mathrm{Y}$ \\
\hline Condon, OR & $\mathrm{CDN}$ & 891 & $\mathrm{Y}$ & $\mathrm{Y}$ & $\mathrm{Y}$ & $\mathrm{Y}$ \\
\hline Prineville, OR & PVE & 969 & $\mathrm{Y}$ & $\mathrm{Y}$ & $\mathrm{Y}$ & $\mathrm{N}$ \\
\hline
\end{tabular}

\section{b. Temperature profilers: Microwave radiometers and RASS}

The WFIP2 field campaign included temperature profiles from 4 microwave radiometer profilers (MWRs) and 11 radio acoustic sounding systems (RASS), accompanying the RWPs. For the current study, the three MWRs and six RASS systems with collocated wind profilers provided temperature $(T)$ and virtual temperature $\left(T_{v}\right)$ profiles, respectively, throughout the majority of the field campaign, as shown in Table 1 and Fig. 3. Virtual potential temperature $\left(\theta_{v}\right)$ was calculated from both instruments, assuming a standard atmospheric profile of pressure with height.

The three MWR sites are part of the near-perpendicular transect from the Columbia River to the south, from RFS at river level ( $62 \mathrm{~m} \mathrm{MSL})$, to WCO, $15 \mathrm{~km}$ south at $458 \mathrm{~m}$ MSL, and CDN, $65 \mathrm{~km}$ southeast at $891 \mathrm{~m} \mathrm{MSL}$. This transect will provide information on the dependence of cold pools on elevation and distance to the lowest point in the basin. The MWRs provide full, retrieved temperature and relative humidity profiles from the surface to $10 \mathrm{~km}$, using a radiosonde climatology and a neural network approach (Solheim et al. 1998a,b; Ware et al. 2003; Rosenkranz 1998) with periodic in situ calibrations. Retrievals were available every 50 to $500 \mathrm{~m}$, then every 100 to $2000 \mathrm{~m}$, and every $250 \mathrm{~m}$ to $10 \mathrm{~km}$. Because the scanning MWRs are passive profiling systems, they have limited information content in the vertical (Löhnert et al. 2009), but that information is concentrated in the lower portion of the profile. Profiles were collected every $2-3 \mathrm{~min}$ and averaged to hourly values with a time stamp at the end of each hour for alignment with RASS measurements (Fig. 3). Previous deployments of MWRs with RASS and in situ temperature sensors showed a mean absolute error of $1.5^{\circ} \mathrm{C}$ in temperature and $R^{2}=0.76$ to 0.91 for lapse rates, with increased errors above $3 \mathrm{~km}$ AGL under rainy conditions (Friedrich et al. 2012; Bianco et al. 2017).

RASS profiles are observed for the last five minutes of each hour by the $915-\mathrm{MHz}$ RWPs, with range gate spacing varying slightly at each of the six sites. The lowest height of measurement is between 115 and
$150 \mathrm{~m}$ AGL, extending up to 1581-1614 m AGL with about $60 \mathrm{~m}$ of vertical resolution for each instrument. The height coverage of RASS profiles is dependent on atmospheric conditions, and measurements are, therefore, not available at all times or to all heights through the cold pool. RASS and MWRs were collocated at two sites, in WCO and CDN, Oregon. An instrument intercomparison shows that all overlapping heights agree with $R^{2}=0.97$ for both sites for time periods when both instruments had high-confidence measurements over the entire field campaign (not shown).

\section{Cold pool example}

A 5-day cold pool episode began in the Columbia basin on 12 February 2017. Synoptic conditions during this episode are represented in Fig. 4. An upper-level ridge axis, shown here at $500 \mathrm{mb}$, propagated eastward from just offshore on 12 February to a position well inland over Saskatchewan, eastern Montana, and eastern Wyoming by 16 February. Existence of a long-wave ridge aloft has been associated with cold pool occurrences in many previous studies (Wolyn and McKee 1989; Whiteman et al. 2001; Zhong et al. 2001). As a result of the progression of the ridge, the winds above the cold pool were mostly less than $10 \mathrm{~m} \mathrm{~s}^{-1}$ during the first three days, but increased to $>15 \mathrm{~m} \mathrm{~s}^{-1}$ from the southwest on 15 February. At the surface a ridge axis moved east into Idaho on 12 February, producing pressure gradients over the basin favorable to easterly flow, which occurs more often in winter than in other seasons (Pichugina et al. 2019). As the surface ridge continued east over the next several days, southwesterly surface flow developed but stayed west of the Cascades until 16 February, when a Pacific cold front passed through the region.

Figure 5 details the cold pool event as experienced at Wasco, OR, where all instruments were operating. Time-height cross sections of $\theta_{v}$ from the MWR (Fig. 5a) and RASS (Fig. 5b) both show the cold, stable layer that began to form on 12 February, and remained until 1800 UTC 16 February. Wolyn and McKee (1989) describe the life cycle of a cold pool 

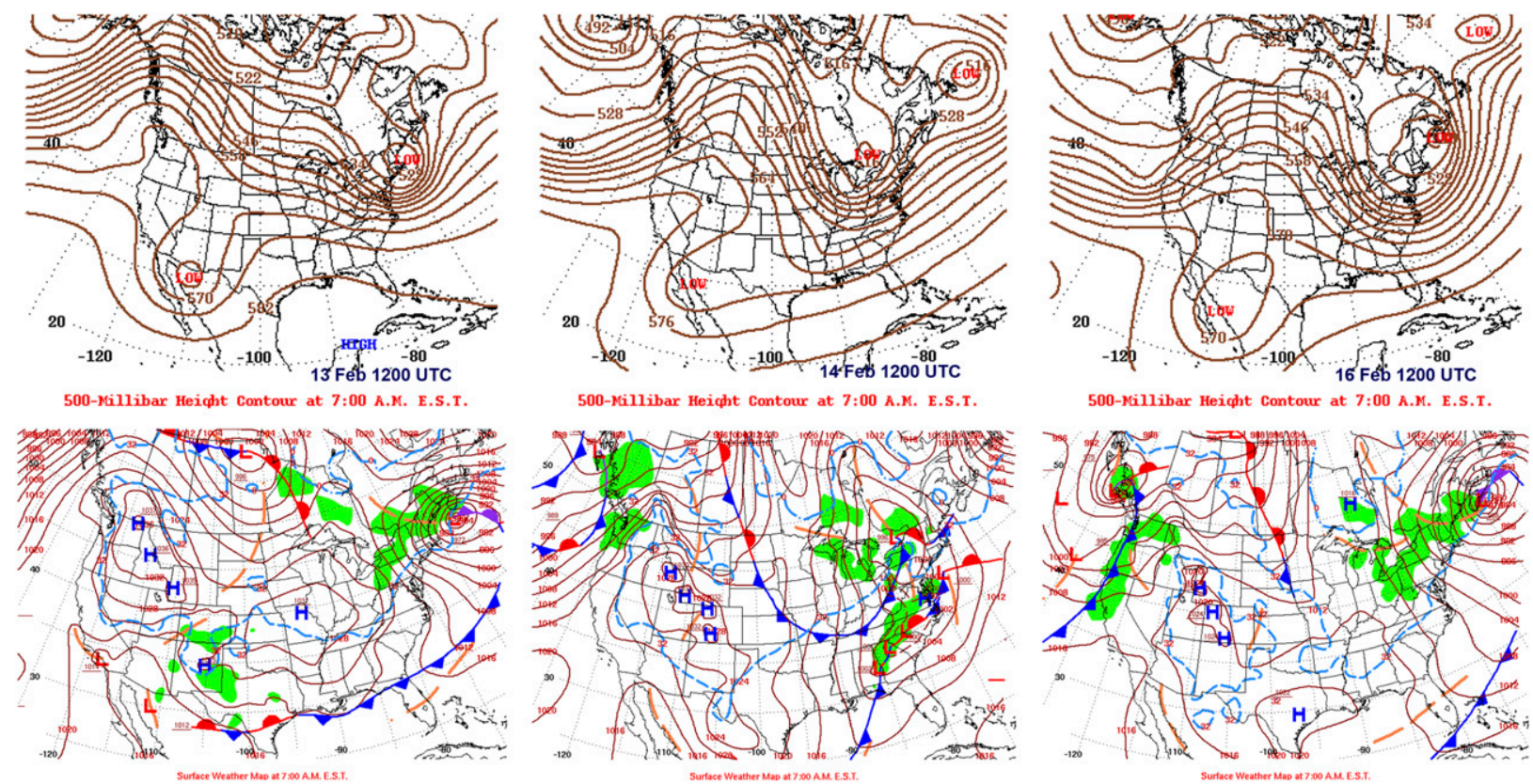

FIG. 4. Synoptic charts representing large-scale conditions for the 12-16 Feb 2017 cold pool event. (top) 500-mb charts for 1200 UTC 12 , 14, and 15 Feb. (bottom) 1200 UTC surface charts for the same days. Source: NOAA/NWS daily weather maps.

event as consisting of initiation, continuation, and termination phases:

\section{a. Initiation}

The cold pool episode began after the ridge had moved across the coast following a Pacific polar front, that left cool air and easterly winds near the surface in the Columbia River basin. These conditions suggest a role for blocking of the cold air against the Cascades in the formation of the cold pool, as found in Whiteman et al. (2001) and Zhong et al. (2001). Before the cold pool set in, wind speed and direction from the $915-\mathrm{MHz}$ RWP (Figs. 5c,d) and the sodar (Figs. 5e,f) show westerly winds of greater than $10 \mathrm{~m} \mathrm{~s}^{-1}$ that diminished, to be replaced by light winds $\left(<3 \mathrm{~m} \mathrm{~s}^{-1}\right)$ from the east-southeast in the lower $200 \mathrm{~m}$ AGL throughout the remainder of the event. Steady warming aloft, continuing for the first four days due to advection or subsidence under the ridge, intensified the stability at the top of the cold air in the basin, as found in many of the previous studies cited.

\section{b. Continuation}

Cold pool winds were light and tended to be easterly, due to a surface trough offshore and higher pressure inland beneath the cold-air dome. Time series show that $d \theta_{v} / d z$ from the MWR (blue line in Fig. 5g) between the lowest measurement and $1000 \mathrm{~m}$ AGL, remained stable over the entire period, and often very stable with $d \theta_{v} / d z>15^{\circ} \mathrm{Ckm}^{-1}$. During nighttime periods of the event, the cold-air pool intensified due to radiational cooling and drainage flows along the basin slopes, but during the day solar heating was insufficient to mix out the strong inversion layer. The time series of wind speeds and directions from the radar (blue and red lines, respectively, Fig. 5h) highlight the cold pool as the period of stagnant air. Each day from 2200 to 0300 UTC (1400-1900 local time) the wind speeds increased but the wind direction remained easterly, advecting cold air within the basin. The cold pool did not mix out, remaining decoupled from the southwesterly winds aloft. The ridge moved eastward on 15 February, yielding to southwesterly flow aloft ahead of the trough moving across the coast, which initially brought in even warmer air aloft, further decoupling the cold pool air from the air aloft.

\section{c. Termination}

As the trough advanced across the basin on 1516 February, the southwesterly winds strengthened aloft, leading to enhanced shear at the top of the cold pool and a steady decline in the depth of the cold pool. Such a steady descent rate, which exposed the higher sites and wind turbines to stronger winds (see next paragraph), is characteristic of turbulent erosion of the cold pool top. In the presence of strengthening winds aloft, however, the descent and consequent exposure of higher sites could also be due in part to the downwind displacement of the cold pool (Whiteman et al. 2001), with a resulting 

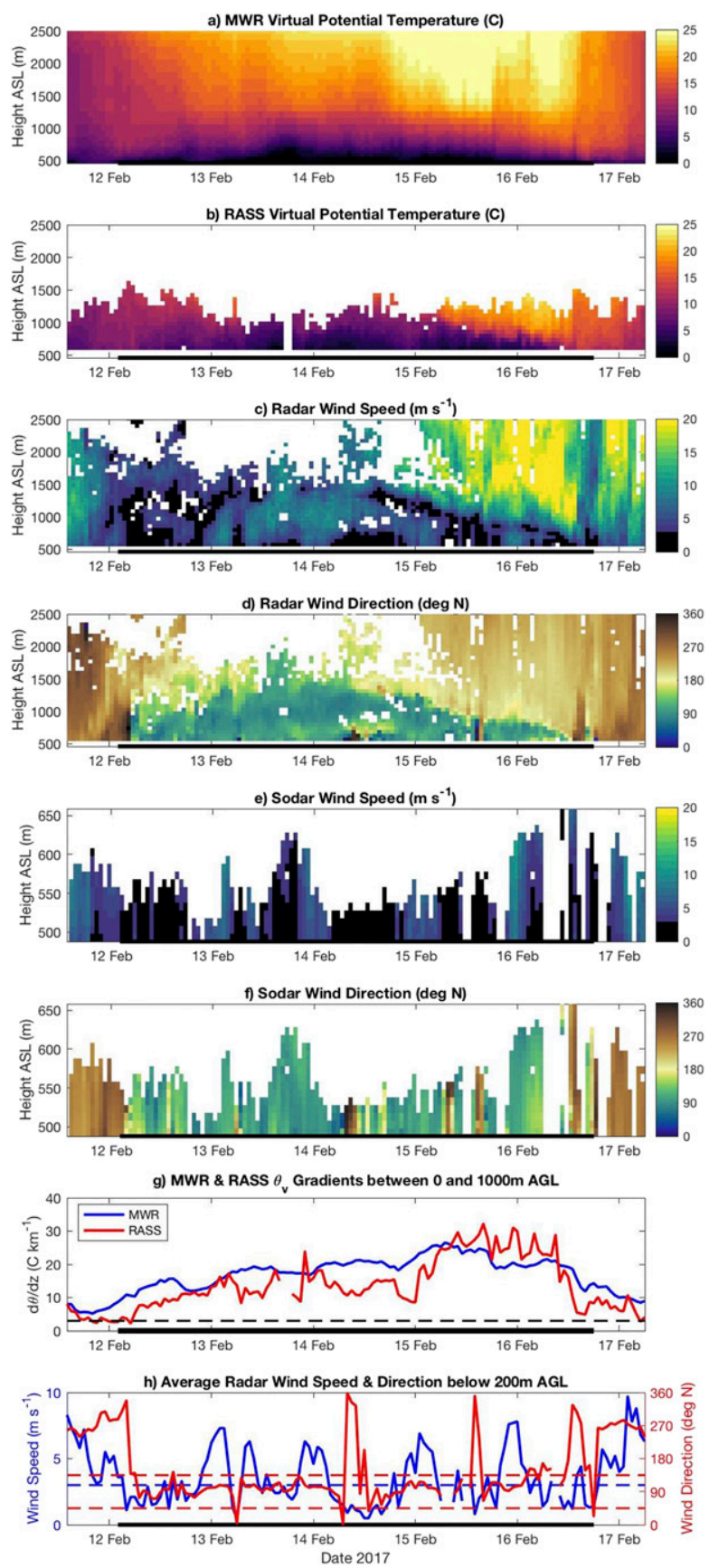

FIG. 5. Time-height cross sections during a cold pool event (marked in black lines at the bottom of each panel) at Wasco, OR, of (a) virtual potential temperature from the MWR, (b) virtual potential temperature from the RASS, (c)-(f) wind speed and direction from the $915-\mathrm{MHz}$ RWP and sodar, (g) MWR (blue) and RASS (red) virtual potential temperature gradients between the ground and $1000 \mathrm{~m} \mathrm{AGL}$, and the threshold for cold pools of $d \theta_{v} / d z>3{ }^{\circ} \mathrm{C} \mathrm{km}^{-1}$ in dashes, and (h) RWP wind speed (blue) and direction (red) averaged in the lower $200 \mathrm{~m}$ AGL, with the thresholds of $3 \mathrm{~m} \mathrm{~s}^{-1}$ and $45^{\circ}$ and $135^{\circ} \mathrm{N}$, respectively, in dashes. tilting of the cold pool top (Zängl 2003; Lareau 2014). To complete the termination phase, late on 16 February, a cold front moved through the basin, reducing the vertical temperature gradient across the cold pool inversion (as visible in Figs. 5a,b) enough that the energetic southwesterlies could mix out the cold-air layer in the basin. At around 1800 UTC at WCO wind speeds increased to greater than $3 \mathrm{~m} \mathrm{~s}^{-1}$-an important threshold, as it is the typical speed at which a wind turbine begins generating power, or cut-in speed (International Electrotechnical Commission 2005). Thus, the combination of the cold front and the strong southwesterly winds allowed the cold pool to finally erode down to the surface at about 1800 UTC. The end of the event was thus marked by southwesterly winds exceeding $10 \mathrm{~m} \mathrm{~s}^{-1}$ throughout the column, including the surface layer, shown in the sodar profiles (Figs. 5e,f).

As shown in Fig. 6, this event was also visible at CDN and PVE, both south of WCO at higher elevations. Figure 6 shows the virtual potential temperature (left) and wind speed profiles (right; with sodar winds plotted up to the lowest RWP measurements) from the three sites, with increasing elevation from top to bottom. The cold pool was present at all three locations, but with varying intensities and durations. As the warm air aloft descended, the higher-elevation sites experienced temperature and wind speed increases earlier in the lowest $200 \mathrm{~m}$ AGL. The wind speeds increased at approximately 1800 UTC 16 February at WCO, at $\sim 1200$ UTC 15 February in CDN, and even earlier at $\sim 2200$ UTC 14 February, in PVE.

This cold pool event thus had a life cycle similar to many described in previous studies. The episode began as a surface ridge line moved to the east, leaving the relatively cool basin air in easterly flow. Blocking and warming aloft isolated the cold pool, basin air, initiating the episode. As the cold pool continued to occupy the basin, the weak winds tended to be easterly, although occasionally the easterlies became strong, exceeding $8 \mathrm{~m} \mathrm{~s}^{-1}$. The persistence of the cold pool during strong easterly flow was unexpected and lends further support for the role of blocking, even during the continuation phase. Termination of the episode was a combined effort, started by turbulent erosion of the top of the cold pool, with possible contributions from cold pool displacement processes. It ended with advection of cooler air into the region, significantly reducing the stability at the top of the cold pool, which allowed the strong shearproduced turbulence to mix out the cold air.

\section{Definition and features of a cold pool}

A quantitative definition of a cold pool is necessary to identify all events during WFIP2. For long datasets that 

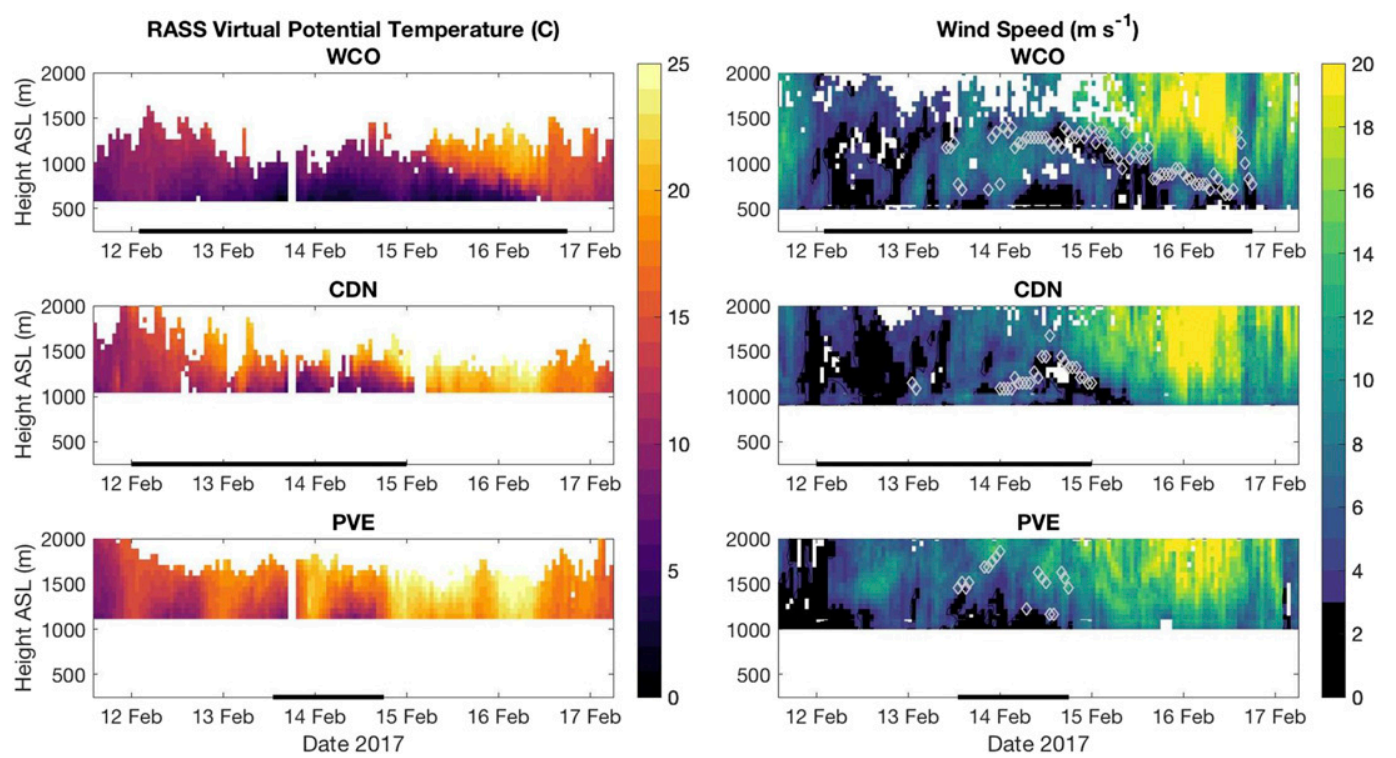

FIG. 6. Time-height cross sections of (left) RASS virtual potential temperature and (right) RWP and sodar wind speeds during the cold pool event from Fig. 5 at three locations moving south from the Columbia River and up in elevation: (top) Wasco, (middle) Condon, and (bottom) Prineville. Gray diamonds on the wind speed plots identify the top of the cold pool as defined with the algorithm described in section $4 \mathrm{~b}$.

span many observing sites, such as WFIP2, it would be beneficial to have an automated algorithm to determine when cold pools are present. The following subsections present the criteria used in the automated cold pool identification algorithm, as well as the cold pool depth and descent rate.

\section{a. Criteria for identification}

Although generally the definition of a cold pool is easily understood as a cold, stable layer near the surface, characteristics of cold pools can vary strongly in time and space. As such, the automated identification of cold pools across multiple instruments over a large area is not straightforward. Previous work by Whiteman et al. (2001) defined a persistent cold pool between two met stations separated by $40 \mathrm{~km}$ and $1000 \mathrm{~m}$ elevation by three criteria: 1 ) a positive vertical temperature gradient between the measurements at the two stations, 2) wind speeds less than $3 \mathrm{~m} \mathrm{~s}^{-1}$ at the lower station, and 3) criteria 1 and 2 have to persist for more than $18 \mathrm{~h}$. With full profiles of temperature and wind speed at each site, in this study we are able to develop a more detailed definition.

Atmospheric stability within the cold pool layer can be measured with the $\theta_{v}$ profiles from the RASS and MWR. Ideally one would like to determine simultaneously whether a cold pool is present together with its characteristics such as depth and bulk stability. Another proposed metric of cold pool strength is the valley heat deficit, an integrated deficit of theta from the surface to the cold pool top (Whiteman et al. 2014). However due to instrument measurement limitations, it is not always possible to measure the tops of cold pools and other relevant quantities, as discussed later in section $4 \mathrm{~b}$. For this reason, we choose to use in our automated algorithm a definition of a cold pool based on the stability between the surface and a fixed height. Using the selected value of the depth over which the bulk stability is measured, one can then use that bulk stability as a criterion to determine whether a cold pool is present. Theoretically, a layer is considered stable under dry conditions (i.e., no condensation) if $d \theta_{v} / d z>0$. Unfortunately, noisy observations, particularly from the RASS, required some revision of this criterion. Multiple thresholds were tested, and with a final chosen threshold of $d \theta_{v} / d z>3^{\circ} \mathrm{C} \mathrm{km}^{-1}$. This looser threshold allowed inclusion of warm-season events, when the nighttime stable layer of the diurnal cycle remained slightly stable into daytime hours, but a stricter threshold would have caused missed events due to imperfect measurements. Although we used different criteria, this is similar to the threshold used in Zhong et al. (2011) of $d \theta_{v} / d z>3^{\circ} \mathrm{Ckm}^{-1}$ and $\mathrm{Yu}$ et al. (2017) of $d \theta_{v} / d z>$ $2.5^{\circ} \mathrm{Ckm}^{-1}$.

The depth of the layer used to calculate the vertical temperature gradient needs to be defined as well, and the availability of profiles rather than isolated points allowed for a scientifically based choice. Three different top heights were tested: a constant height of $1500 \mathrm{~m} \mathrm{MSL}$, since that is the approximate height of the 
surrounding topography in which the cold pool settles; $500 \mathrm{~m} \mathrm{AGL}$, which is well within the cold pool layers at all locations at most times; and $1000 \mathrm{~m}$ AGL, which is within the cold pool at some locations but above it at others much of the time. All three cases have occasional periods when the RASS does not observe up to the desired height, in which case for this instrument, the highest available measurement was used, while requiring a minimum of 3 measurements in the profile. Although slight differences exist in the number of hours that meet the $d \theta_{v} / d z$ criterion for the three different top heights, all three identify the same events $80.5 \%$ of the time. Figure 7 shows an interesting event when daytime surface heating on 22 and 23 November caused the growth of the convective boundary layer to $500 \mathrm{~m}$ AGL (blue lines), creating a less stable $d \theta_{v} / d z$ that does not meet the criterion, but $d \theta_{v} / d z$ between the ground and $1000 \mathrm{~m}$ AGL (green lines) or $1500 \mathrm{~m}$ MSL (red lines) remains stable for the duration of the cold pool. In total, the resulting events identified using $1500 \mathrm{~m}$ MSL and $1000 \mathrm{~m}$ AGL as top heights only differed $11 \%$ of the time. When comparing to the WFIP2 event log (Shaw et al. 2019), we found that the best agreement in event identification occurred when using $1000 \mathrm{~m}$ AGL as the top height. Thus, the virtual potential temperature gradient used for identifying cold pools was calculated between the lowest level of the instrument and $1000 \mathrm{~m}$ AGL (or if the RASS does not reach $1000 \mathrm{~m}$, the highest available measurement, with at least 3 measurements in the profile).

Although stable vertical potential temperature gradients are the primary indicator of a cold pool, wind speed and direction also play a crucial role in the occurrence of this phenomenon in the Columbia River basin. Whiteman et al. (2001), whose study occurred in this same general geographical location, required that the wind speeds at the lower-elevation site, regardless of direction, be less than $3 \mathrm{~m} \mathrm{~s}^{-1}$. However, as seen at times during the sample event shown in Fig. 5, easterly winds within the stable layer can be stronger than that, and not mix out the cold pool because they typically advect in cold low-level air. Therefore, in our algorithm, easterly winds were allowed to be at or above the threshold of $3 \mathrm{~m} \mathrm{~s}^{-1}$, but winds from the southeast west northeast must be below the threshold. It should be noted that the wind direction criterion defined here is unique to the WFIP2 portion of the Columbia River basin, since the easterly winds are perpendicular to the Cascade Mountains, which run north-south. Other locations may experience persistent cold pools with advection of cold low-level air from different wind directions, and therefore the automated identification algorithm should be modified accordingly. The wind speed criterion was applied to sodar and RWP wind speeds and
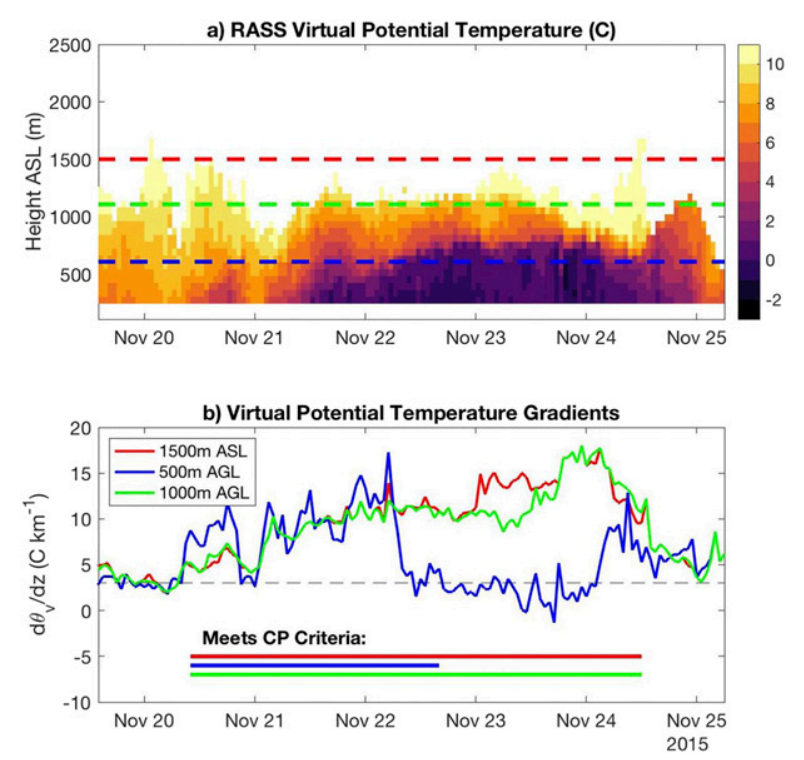

FIG. 7. (a) Time-height cross section of RASS virtual potential temperature at Boardman, OR, with red, green, and blue dashed lines at $1500 \mathrm{~m}$ MSL, $1000 \mathrm{~m}$ AGL, and $500 \mathrm{~m}$ AGL, respectively, marking the top of the (b) virtual potential temperature gradients. Horizontal lines in (b) show when each time series of $d \theta_{v} / d z$ meets the criterion for a cold pool of $3^{\circ} \mathrm{C} \mathrm{km}^{-1}$.

directions averaged below $200 \mathrm{~m}$, to represent the winds at turbine height.

The third criterion of Whiteman et al. (2001), addressing event duration, was also slightly tightened, requiring the first two conditions to be present for at least $20 \mathrm{~h}$ to exclude the common nighttime stable layer with calm winds, seen in summertime in the Columbia River basin. Interruptions, mostly due to noisy measurements, were allowed within an event but could not exceed three consecutive hours.

To summarize, in this study a cold pool is identified if the hourly observations of wind speed, wind direction and temperature meet all three of the following criteria:

1) $d \theta_{v} / d z>3^{\circ} \mathrm{C} \mathrm{km}^{-1}$ between the lowest measurement and $1000 \mathrm{~m}$ AGL (or the highest available measurement for RASS measurements, with at least 3 measurements in the profile);

2) average wind speeds below $200 \mathrm{~m}$ AGL are $<3 \mathrm{~m} \mathrm{~s}^{-1}$, except if the direction is easterly (between northeast and southeast), where no threshold is applied; and

3) the event lasts longer than $20 \mathrm{~h}$, with short ( $\leq 3$ hours) interruptions allowed.

These criteria to define the existence of a cold pool were used to identify all cold pool events during the WFIP2 field campaign. Among these was the event shown in Fig. 5, where the time period identified by the automated algorithm is shown in solid black lines 
at the bottom of each panel. Thresholds for $d \theta_{v} / d z$ and wind speed and direction are also shown as dashed lines on their respective panels. Although the lapse rate time series remain above the threshold of $3^{\circ} \mathrm{C} \mathrm{km}^{-1}$ throughout the entire period shown (Fig. $5 \mathrm{~g}$ ), the wind speed criterion determines the end of the cold pool event, when at around 1800 UTC on 16 February, the winds shift to westerly and increase. Similarly, black solid lines at the bottom of each panel in Fig. 6 define the duration of the cold pool by the above criteria, showing how the length of the cold pool event can vary depending on the site.

\section{b. Cold pool depth}

The depth of a cold pool is an important metric because it impacts the duration of events and determines whether all or a portion of a wind plant will be immersed in a cold pool or not. It is important for NWP models to properly predict this depth to accurately predict wind speeds in the turbine rotor layer (Pichugina et al. 2019). Identifying the depth of the cold pool was investigated using different approaches. The transition between cold surface temperatures and low wind speeds to the ambient warmer temperatures and high wind speeds aloft produces large temperature and wind speed gradients at the cold pool top. Figure 8 shows the gradients (calculated using a centered difference, with one-sided differences at the top and bottom of the profiles) of $\theta_{v}$ from MWR (Fig. 8a) and RASS (Fig. 8b) and the RWP wind vector (defined as $d \mathbf{V} / d z=\sqrt{\Delta u^{2}+\Delta v^{2}} / \Delta z$, where $\mathbf{V}$ is the wind vector, $u$ is the east-west component, $v$ is the north-south component, and $z$ is the height between RWP measurements in meters; Fig. 8c). In each panel, filled symbols mark the peak in the quantity plotted, whereas for comparison, the peaks in the quantities are shown as open symbols on the other panels. Unfortunately, the profiles from the passive retrieval technique of the MWR are too smooth, with a peak gradient occurring at the surface, but not at the top of the cold pool (magenta squares). However, RASS $\theta_{v}$ (filled green circles in Fig. $8 \mathrm{~b}$ ) and RWP wind speed (filled cyan diamonds in Fig. 8c), exhibit an obvious peak in the gradients aloft, especially as the cold pool top descends.

Although the RASS virtual potential temperatures and RWP winds show the clear transition at the cold pool top, the instruments, particularly the RASS, often do not observe the entire cold pool depth during the bulk of the event, and thus searching for a peak in $d \theta_{v} / d z$ can incorrectly identify the top. Applying a minimum threshold of $25^{\circ} \mathrm{C} \mathrm{km}^{-1}$ for $d \theta_{v} / d z$ or $4\left(\mathrm{~m} \mathrm{~s}^{-1}\right) \mathrm{km}^{-1}$ for wind vector gradients removes these unrealistic tops. The RWP winds typically have better vertical coverage than the RASS, and the maximum gradient is visible throughout more of the event (cyan diamonds).
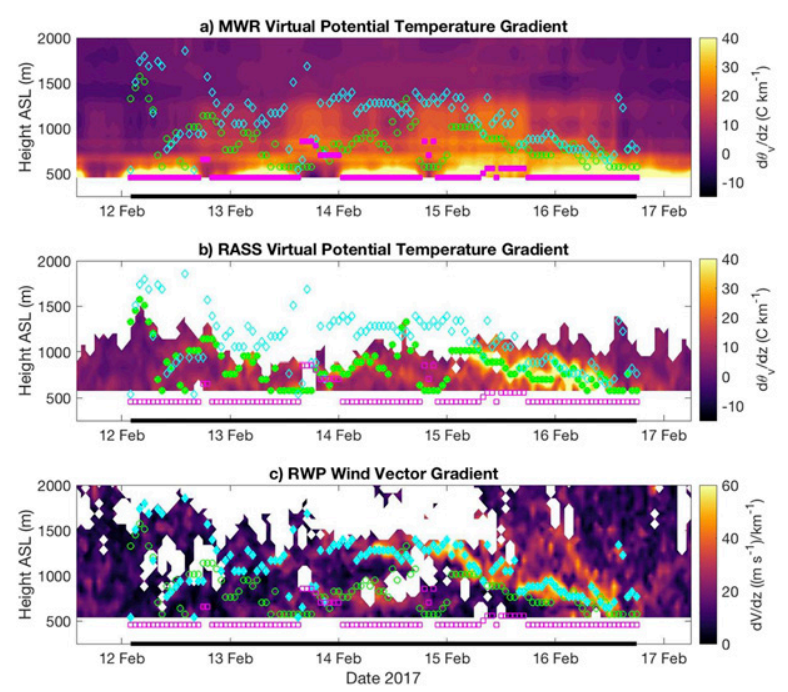

FIG. 8. Time-height cross sections of (a) virtual potential temperature gradient from the MWR, (b) virtual potential temperature gradient from the RASS, and (c) the magnitude of the vector wind gradient from the $915-\mathrm{MHz}$ RWP at WCO for the same event in Figs. 5 and 6. Magenta squares, green circles, and cyan diamonds mark the top of the cold pool as identified using the MWR virtual potential temperature, RASS virtual potential temperature, or RWP wind vector, respectively, as described in section $4 \mathrm{~b}$, though with no limit applied. Shapes are filled on their respective plots.

With the goal of improving forecasts of wind speeds in WFIP2, the drastic change in wind speed and direction is most crucial in identifying when a cold pool has eroded. Therefore, with the above-mentioned application of a temperature or wind vector gradient threshold to remove unrealistic cold pool tops (mainly through the creation and maintenance time periods of the event), the peak in the wind vector gradient is used in the following analysis to measure the depth of the cold pool. It is interesting to note that the peak in the wind vector gradient (cyan diamonds) tends to be slightly higher than the peak in $d \theta_{v} / d z$ from the RASS (green circles). This suggests that the turbulent shear layer at the cold pool boundary transfers heat down into the upper cold pool where wind speeds remain small (Lareau and Horel 2015a). Although the wind vector gradient from the RWP is the best method for identifying the top of cold pools for this study, future analyses could employ different quantities (temperature, wind speed, and direction) at the same time through fuzzy logic, neural network, or neuro-fuzzy hybridization techniques, to identify cold pool tops more accurately, similar to the boundary layer depth identification method of Bianco and Wilczak (2002).

The gray diamonds in Fig. 6 show the top of the cold pool as identified by the peak in wind vector gradient from the RWP at all three locations. From this example, 

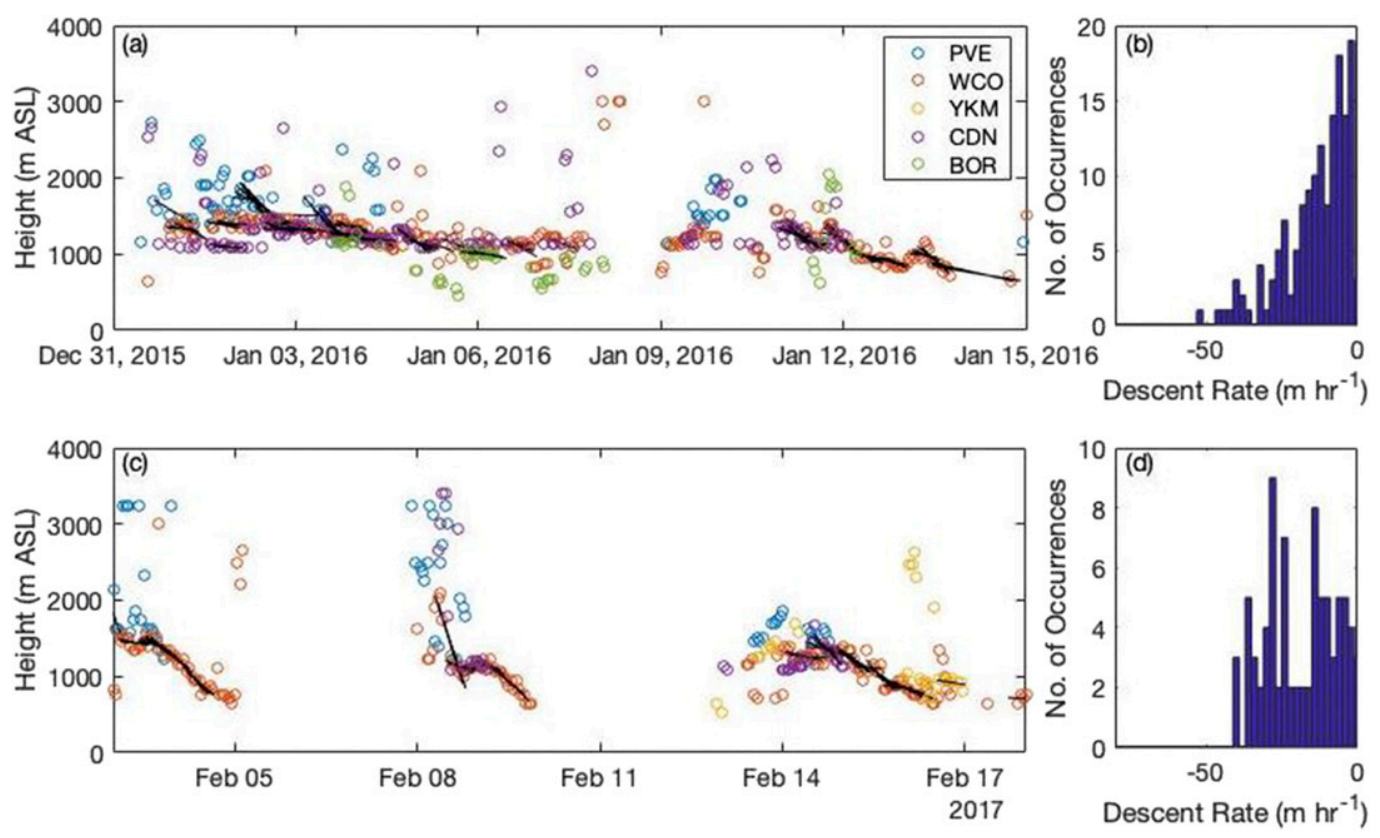

FIG. 9. (a),(c) Cold pool tops as identified by the peak in the RWP wind vector gradient at five RWP locations (PVE: blue, WCO: red, YKM: yellow, CDN: purple, BOR: green) during two 2-week periods with multiple cold pool events, with 12-h least squares fit lines in black. (b),(d) Distributions of descent rates (slopes of least squares fit lines) for each 12 -h period with a discernible descent rate.

the top of the cold pool as identified by our method seems to be more reliable in the decay phase of the cold pool, as the peak in gradients descends in height. Even though the depths of the cold pools are not available throughout the entire duration of the event, they still provide valuable information. For instance, the depths of the cold pool above the ground in Fig. 6 are quite different at the three locations. At WCO, the decay is visible for three days before the end of the event, while at CDN, it only takes about one day for the cold pool to erode. In PVE, which is at higher elevation, the wind vector gradient is less intense at the top than at the other sites, so the depth of the cold pool is not accurately measured. Although the WCO and CDN sites differ in elevation by $450 \mathrm{~m}$, the beginning of the decay of the event occurs in both cases at just below $1500 \mathrm{~m}$ MSL, which is approximately the maximum height of the surrounding topography. This common depth above sea level will be discussed further in section $5 \mathrm{~d}$. Finally, we note that because the cold pool top cannot always be identified, the bulk stability to a common height must be used for the identification of the entire cold pool event, but the top of the cold pool will be analyzed separately.

\section{c. Cold pool descent rate}

Multiple processes can impact the depth of the cold pool, especially at the end of a cold pool event, as it decreases and the cold pool top descends. Turbulent erosion due to wind shear at the boundary (Zängl 2003; Lareau and Horel 2015a,b) and subsidence from the overlying high-pressure ridge (Wolyn and McKee 1989; Lareau et al. 2013) both lead to this descent, as well as cold advection aloft. Here, we discuss the rate at which the cold pool boundary descends toward the windturbine layer.

Using the above-defined tops of the cold pool, the rate that the cold pools descend can be computed. A least squares fit was performed on running blocks of 12-h cold pool top heights throughout each event, after removing points that exceeded three standard deviations from the mean of the 12-h set. The identified tops can be fairly variable in time, especially at high-elevation locations (PVE), where cold pools are not as persistent, and low elevations (e.g., BOR), where the RWP does not often see the top of the cold pool. Therefore, fits of the $12-\mathrm{h}$ lines with a root-mean-square error of more than $10 \%$ of the average of the observed values were discarded. The descent rate is defined here only at times when the cold pool top is, in fact, descending; therefore, positive slopes to fit lines during periods when the cold pool is deepening are not included. The rate at which the descent of a cold pool top happens can be very different from event to event. For instance, in Fig. 9 we show two two-week periods when the descent of cold pool tops is evident at multiple sites. Although the descent of the cold pool top during the January 2016 event occurred 


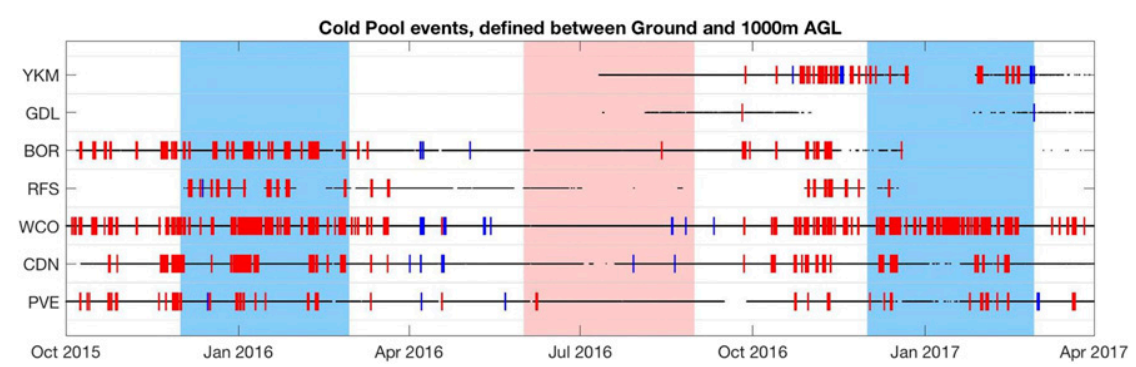

FIG. 10. Time series of all cold pool events as identified from MWR, RASS, RWP, and sodar observations. Red bars show the duration of cold pool events, and black lines show when temperature and wind speed data were available. Blue bars show the events identified by the criteria, but removed after comparison with the event log. Light blue shading is DJF and light red shading is JJA.

over several days (Fig. 8a), with the most common descent rate of about $4 \mathrm{~m} \mathrm{~h}^{-1}$ (Fig. 9b), the February 2017 period contains three cold pool events that erode much faster (Fig. 9c), with a bimodal distribution of descent rates that peaks at 16 and $30 \mathrm{~m} \mathrm{~h}^{-1}$ (Fig. 9d). For comparison, the simplified model of Zhong et al. (2003) predicts a range of descent rates of $8-16 \mathrm{~m} \mathrm{~h}^{-1}$ for a $15 \mathrm{~m} \mathrm{~s}^{-1}$ ambient wind speed. For both examples though, and as noted before, the shared cold pool tops MSL at all locations suggest a common depth above sea level.

\section{Identification and statistics of WFIP2 cold pool events}

Identification of all persistent cold pools that occurred over the 18 month field campaign allows for a statistical analysis of the characteristics of this phenomenon. Using the criteria defined in section $4 \mathrm{a}$ applied to the available temperature and wind speed profiles from 1 October 2015 to 31 March 2017, all cold pool events identified at the seven locations are shown in Fig. 10. The thin black lines indicate the availability of the temperature and wind speed measurements needed for identification, and the red bars show the occurrence of cold pools. It is clear that the lack of simultaneous wind and temperature measurements, particularly at GDL, but also at YKM during the winter of 2016, and at YKM and RFS during the winter of 2017, prevents identification of many cold pools. Nevertheless, a total of 232 events were identified at the seven locations: 25 at YKM, 2 at GDL, 36 at BOR, 20 at RFS, 78 at WCO, 34 at CDN, and 37 at PVE. The 232 individual events were analyzed and divided into 61 independent events, most of which were seen at multiple observing sites. Of the 61 events, 27 occurred during winter months (DJF), 21 in fall (SON), 11 in spring (MAM), and 2 in summer (JJA). Comparison to the cold pools documented by meteorologists in the event log showed good agreement, although the quantitative method here identified some weaker cold pools that were not identified in the event log. A total of 33 individual events identified by the criteria in section 4 a were eliminated after comparison with the event log and were removed from further analyses (those shown in blue in Fig. 10). These events occurred mainly in warm months when a nighttime stable layer with weak winds remained into the late morning, barely meeting the $20 \mathrm{~h}$ criterion. Since many events were interrupted or truncated by instrument outages, the number and duration of events found in this study at each site cannot be considered to be an accurate representation of the absolute frequency of the phenomenon in the basin. Similarities and differences across the observing sites will thus be analyzed with other metrics.

\section{a. Wind speed and direction}

Under cold pool conditions, the wind speed and direction behave differently than during normal stable-unstable diurnal cycles. Distributions of wind speed and direction below $200 \mathrm{~m}$ from sodars in Fig. 11 show how the behavior differs between cold pool conditions (red) and throughout the entire field campaign (black). Typically in the Columbia River basin, winds are bimodal out of the east or west-southwest (Pichugina et al. 2019). In cold pools, the wind speeds are predominantly out of the east (as seen in Fig. 11 right panels), particularly at WCO, CDN, and PVE). This is partially enforced by the identification algorithm, but slower westerly wind speeds are possible as well. Figure 11 shows that weak westerly winds are as likely to occur during cold pools as easterly winds at YKM, BOR, and RFS. These sites are unique in their geographical locations; RFS and BOR are at river level (Fig. 2), where cold pools are the deepest, most persistent, and therefore experience the most stagnant winds. At WCO and CDN, easterly winds occur during cold pools, with few additional occurrences of easterly winds outside of these events. In most locations, 

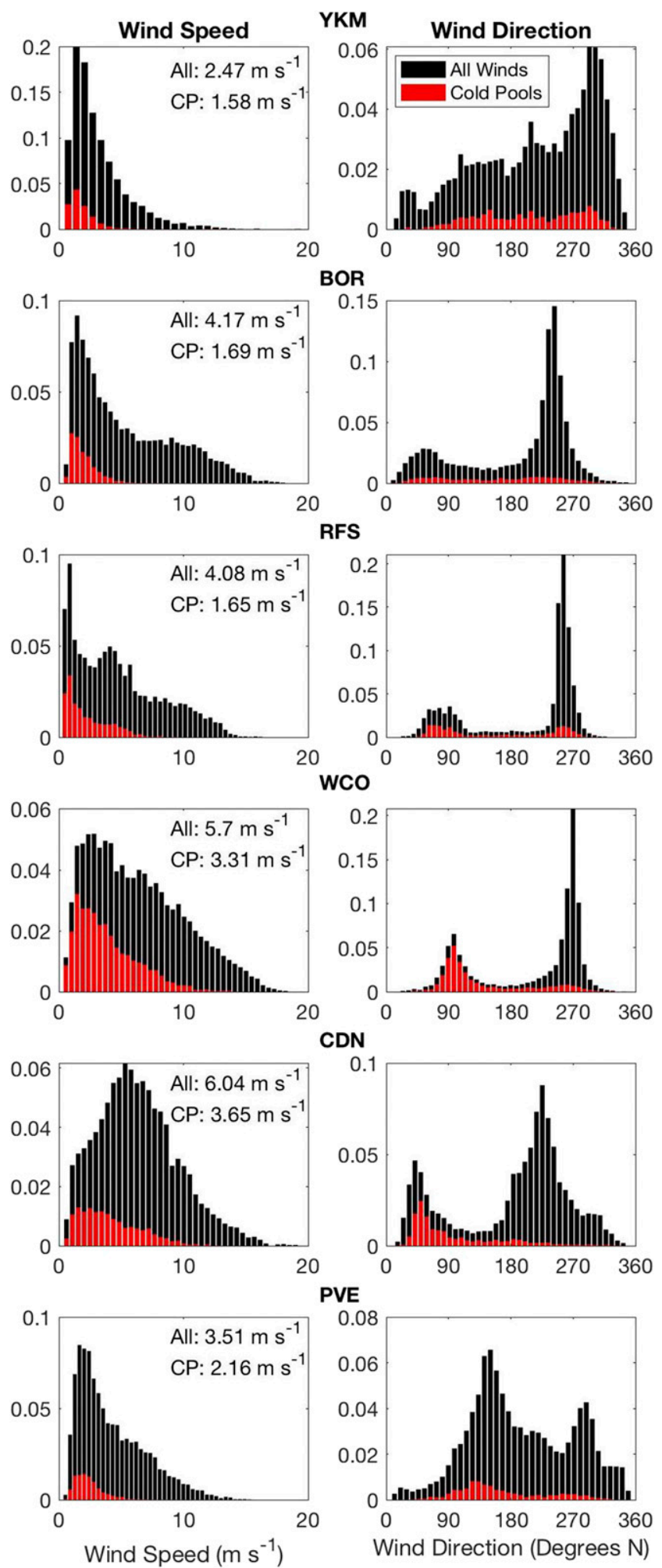

FIG. 11. Histograms of average (left) wind speed and (right) direction below $200 \mathrm{~m}$ at six sodar sites during cold pools (red) and for all conditions (black). The median wind speed of each distribution is shown for each location. 

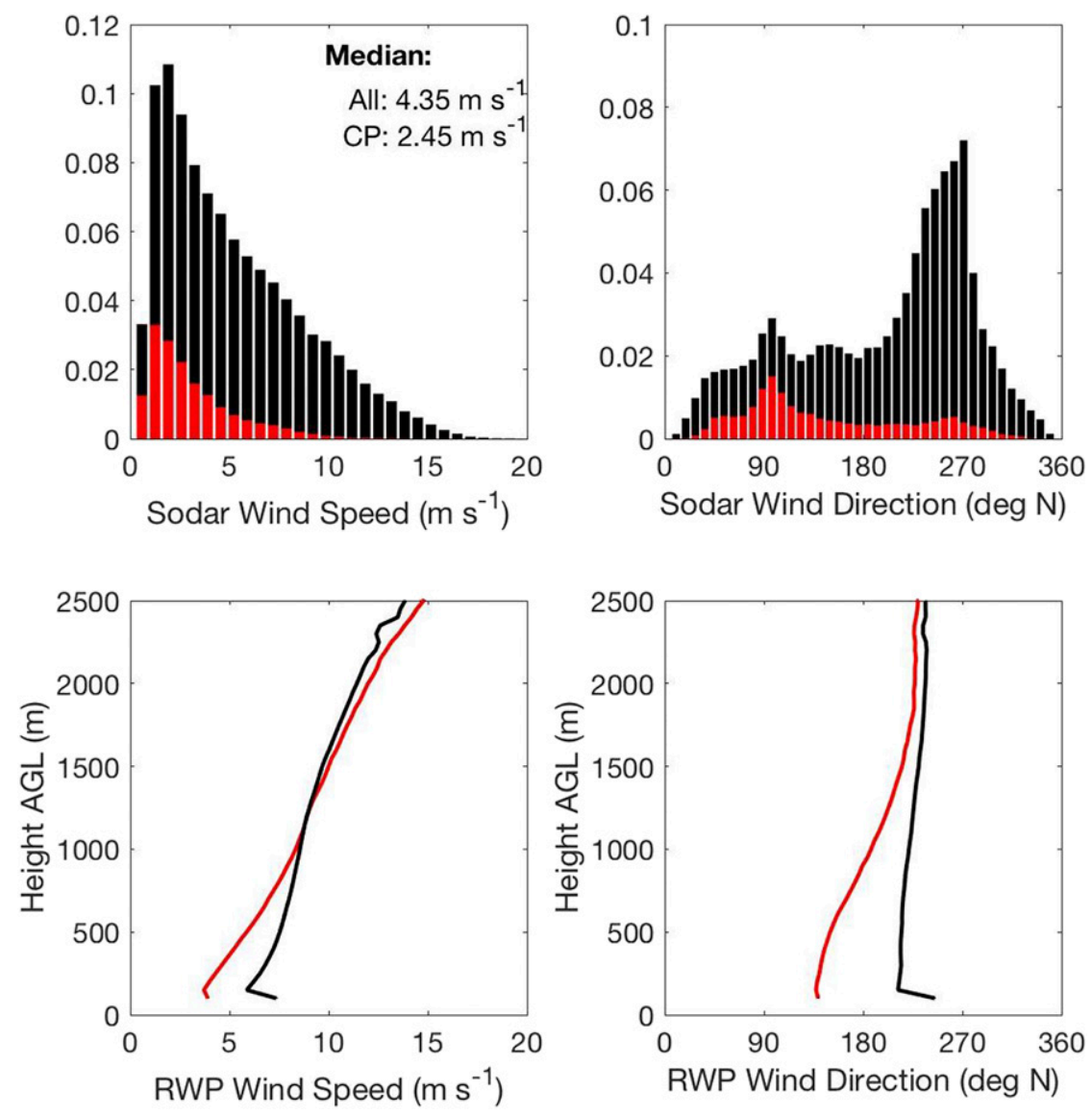

FIG. 12. (top) Histograms of average (left) wind speed and (right) direction below $200 \mathrm{~m}$ AGL at all six sodar sites for cold pool conditions (red) and all conditions, including cold pools (black), with median wind speeds shown. (bottom) Average profiles of (left) wind speed and (right) direction at all six 915-MHz RWP sites, for cold pool conditions in red and noncold pools conditions in black.

although the threshold for westerly winds is $3 \mathrm{~m} \mathrm{~s}^{-1}$, wind speed observations occasionally exceed $3 \mathrm{~m} \mathrm{~s}^{-1}$, signifying the occurrence of stronger easterly winds. YKM, BOR, and PVE, which are farthest north, south, and east, respectively, from the Columbia River Gorge, do not see many of these faster easterly winds, but experience winds from all directions during cold pools, with very few wind speeds above $3 \mathrm{~m} \mathrm{~s}^{-1}$ (Fig. 11 left panels). The cumulative distributions of the winds at all sodar sites is shown in the top panel of Fig. 12, illuminating the predominantly easterly winds that make up the cold pools, but do not occur often under other conditions across the region.

Average profiles of wind speed and direction up to $2500 \mathrm{~m}$ AGL from all six RWPs also differ during cold pool events, as compared to noncold pool conditions (Fig. 12, bottom panels). The wind speeds in the lower $1500 \mathrm{~m} \mathrm{AGL}$ are up to $3 \mathrm{~m} \mathrm{~s}^{-1}$ slower during cold pool events than noncold pool periods, and a more southeasterly wind direction. Above $2200 \mathrm{~m}$ AGL, however, during cold pools the wind speeds are slightly faster than noncold pool conditions, and the wind direction converges to the same predominant west-southwesterly flow aloft.

The ramp up in wind speed from immediately before to just after the cold pool decay is also significant. Figure 13 shows the distributions of sodar $80-\mathrm{m}$ wind speed $6 \mathrm{~h}$ before (Fig. 13a) and after (Fig. 13b) the end of all cold pool events. $70 \%$ of the wind speeds $6 \mathrm{~h}$ after a cold pool are above cut-in speed $\left(3 \mathrm{~m} \mathrm{~s}^{-1}\right)$, and are therefore generating power, whereas only $30 \%$ generated power before the cold pool decayed. Though on average, the wind speed only rises from 2.68 to $5.35 \mathrm{~m} \mathrm{~s}^{-1}$ (from $0 \%$ to $6 \%$ of rated power on the International Electrotechnical Commission power curve), many postevent wind speeds exceed $10 \mathrm{~m} \mathrm{~s}^{-1}$ (78\% of rated power). The fact that wind ramps do not always occur with the descent of a cold pool top makes accurate power forecasting during this time interval even more difficult. 


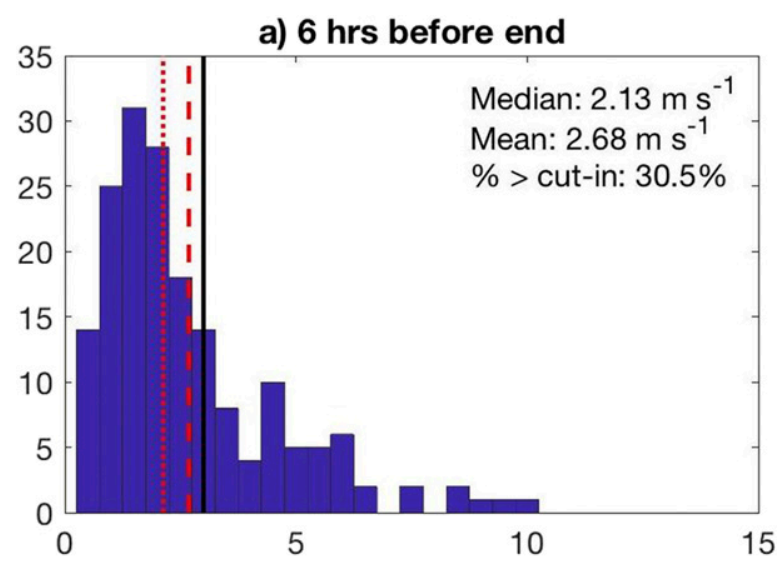

b) 6 hrs after end

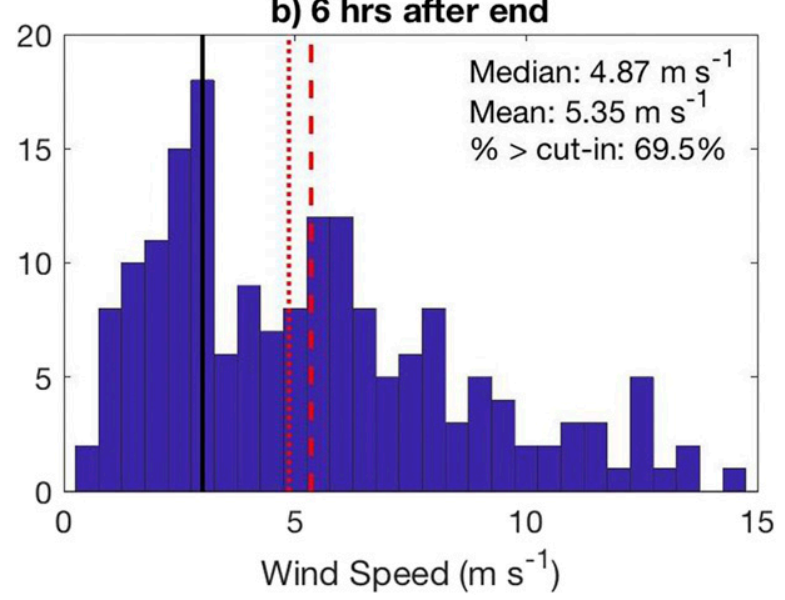

FIG. 13. Histograms of sodar 80-m wind speed at all seven sites $6 \mathrm{~h}$ (a) before and (b) after the end of all cold pool events. Black solid line demarks the cut-in speed of $3 \mathrm{~m} \mathrm{~s}^{-1}$, red dashed lines are the median, and red dotted lines are the mean of each distribution. Median, mean, and percent of distribution above cut-in speed are labeled.

\section{b. Descent rate}

The statistical analysis of descent rates (the slope of the 12-h least squares fits to the height of the cold pool top) throughout WFIP2 shows large variability, as expected. The distribution of descent rates for all sites is shown in Fig. 14, with mean and median descent rates of -20.47 and $-15.91 \mathrm{~m} \mathrm{~h}^{-1}$, respectively. Considering the varied descent rates in the events in Fig. 9, the multiple peaks in the distribution in Fig. 14 are probably not statistically significant, showing that no shared descent rate exists across all events and sites. Descent rate could depend on many different meteorological factors such as the stability within the cold pool, strength of winds and stability aloft, speed of passing synoptic features, variability in wind speeds within the cold pool, etc. The large number of degrees of freedom means that the duration of an event cannot be predicted by the depth, since the descent rate is too variable.

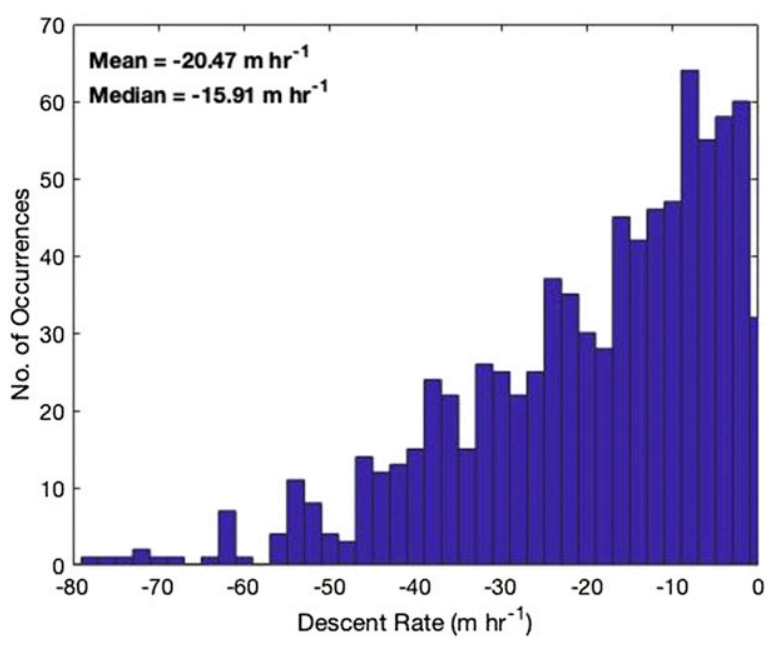

FIG. 14. Distribution of descent rate as defined in section $4 \mathrm{c}$ from five RWP sites over all cold pool events. Mean and median descent rate are shown.

\section{c. Stability}

Stability within a cold pool is its main defining characteristic, allowing the winds to diminish and the cold pool to remain in place for multiple days. The deep cold pools in the Columbia River basin remain very stable, as shown in Fig. 15. The joint probability distribution between stability $\left(d \theta_{v} / d z\right.$ from RASS) and the height of the top of the cold pool shows that, although the cold pool depth has a significant peak at $1100 \mathrm{~m}$ MSL (and median of $1250 \mathrm{~m} \mathrm{MSL}$ ), stability has a range from stable to very stable, with a median of $13.7^{\circ} \mathrm{C} \mathrm{km}^{-1}$, and is often much larger. The single peak in the height of the top of the cold pools, despite the data coming from five locations differing in elevation up to $800 \mathrm{~m}$, is the first statistical indicator of the constant height above sea level of the cold pool top shared by all RWP sites.

\section{d. Elevation dependence}

Since the Columbia River Gorge provides only a narrow outlet for the dense lower-level air, the lowest elevation locations are expected to see the most frequent, longest-lasting, and deepest cold pools. Due to many missed or truncated events due to gaps in observations, we cannot make direct comparisons of the duration of each event at different locations. However, we can analyze the relative frequency of cold pool conditions at each location using the 5-month period from 15 October 2015 to 15 March 2016, when the hourly observations at WCO (458 m MSL), CDN (891 m MSL), and PVE (969 m MSL) were available at all three sites for $90 \%$ of the time. During this period when all three sites provided data, cold pool conditions existed at WCO for $50.97 \%$ of the hours, while, CDN at $450 \mathrm{~m}$ 


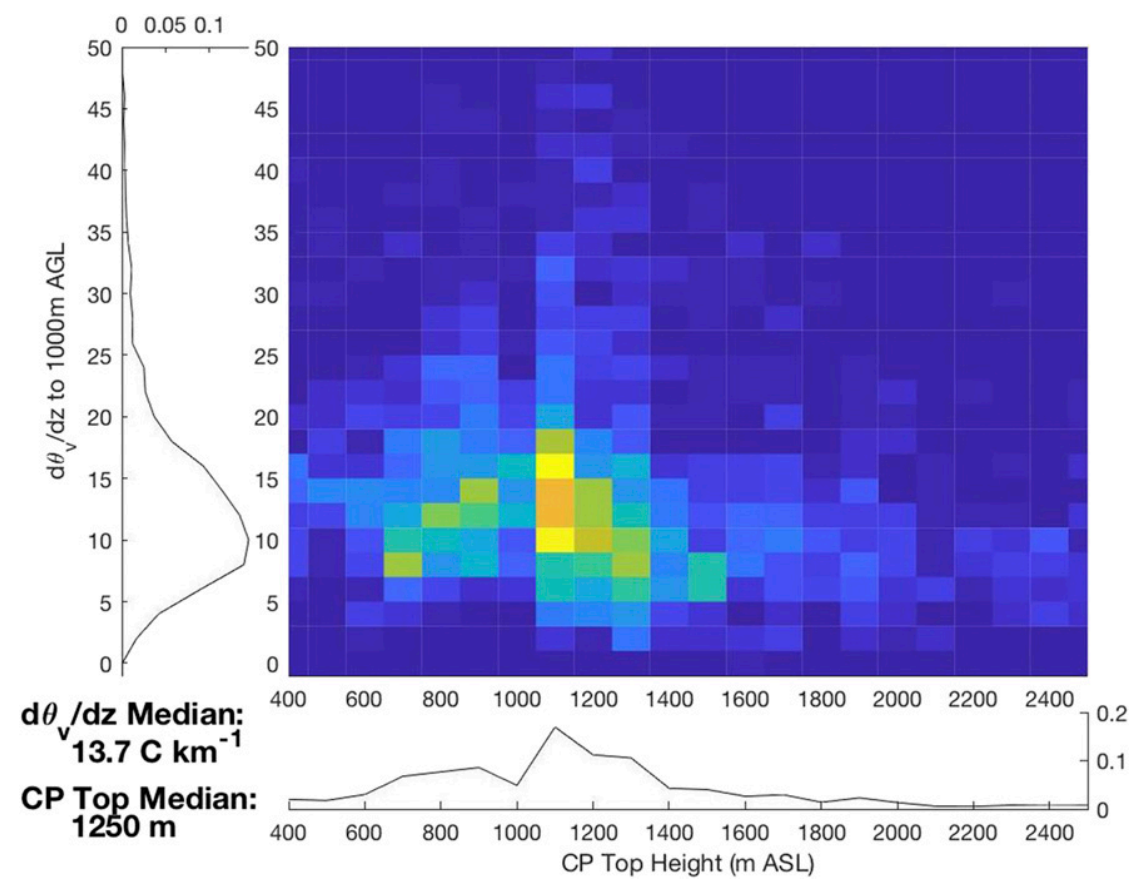

FIG. 15. Joint probability distribution of stability $\left(d \theta_{v} / d z\right.$ between the lowest measurement and $1000 \mathrm{~m}$ AGL or the highest measurement from RASS) and top height of cold pools, for all cold pool events at all five RWP/RASS locations. Individual distributions of each quantity are shown along the respective axes, and median descent rate and cold pool top height are shown.

higher in elevation only experienced cold pool conditions $27.1 \%$ of the time, and another $70 \mathrm{~m}$ higher, PVE experienced cold pools $18.19 \%$ of the time. The availability of observations at three sites with differing elevations confirms, as reasonably could be expected, that lower-elevation sites experience the cold air of cold pools more often than sites at higher elevations.

Finally, throughout the 18 months of identified cold pools, sufficient observations of the cold pool top from the RWP wind vector gradient method are available to statistically support a physical description of the phenomenon. The RWPs in WFIP2 were located at elevations that differ up to $800 \mathrm{~m}$ within a basin surrounded by features of 1200-1500 m MSL (see Fig. 2). If the top of the cold pool is at a constant height relative to sea level, then the differences in cold pool height MSL between pairs of locations will be small, but the differences in depth AGL will be larger and more variable. If the top of the cold pool follows the terrain (which may not be possible without generating large horizontal pressure gradients and hence surface hydraulic phenomena), the differences in height MSL between sites will be larger but the differences in depth AGL will be small. Over 18 months of cold pools, the difference in height MSL and depth AGL at all pairs of sites experiencing a cold pool is shown in Fig. 16. The median difference in height MSL is much smaller than the median difference in depth
AGL, and the distribution is much narrower. Using the cold pool top defined by the maximum RASS temperature gradient also produces this behavior (not shown). This is statistically significant evidence of a constant top height MSL (flat surface) of the cold pool across the region, especially as it decays, since this is when the majority of tops are clearly identified.

\section{Conclusions}

During the Second Wind Forecast Improvement Project, extensive profiling instrumentation observed temperatures and winds during cold pool events, allowing for the first time, a detailed characterization of this impactful phenomenon that is often poorly forecast. Collocated temperature and wind profiles at seven sites provided observations over two cold-season periods with many persistent cold pools. An automated algorithm was developed to identify all cold pool events that meet all of the following criteria: 1$)$ stable layer $\left(d \theta_{v} / d z>\right.$ $3^{\circ} \mathrm{C} \mathrm{km}^{-1}$ ) between the lowest measurements and $1000 \mathrm{~m}$ AGL (or the highest available measurement for RASS measurements, with at least 3 measurements in the profile); 2) average wind speeds below $200 \mathrm{~m}$ are $<3 \mathrm{~m} \mathrm{~s}^{-1}$ except if the direction is easterly (between northeast and southeast), where no threshold is applied; 3 ) duration of more than $20 \mathrm{~h}$. This is a more robust definition of a cold 


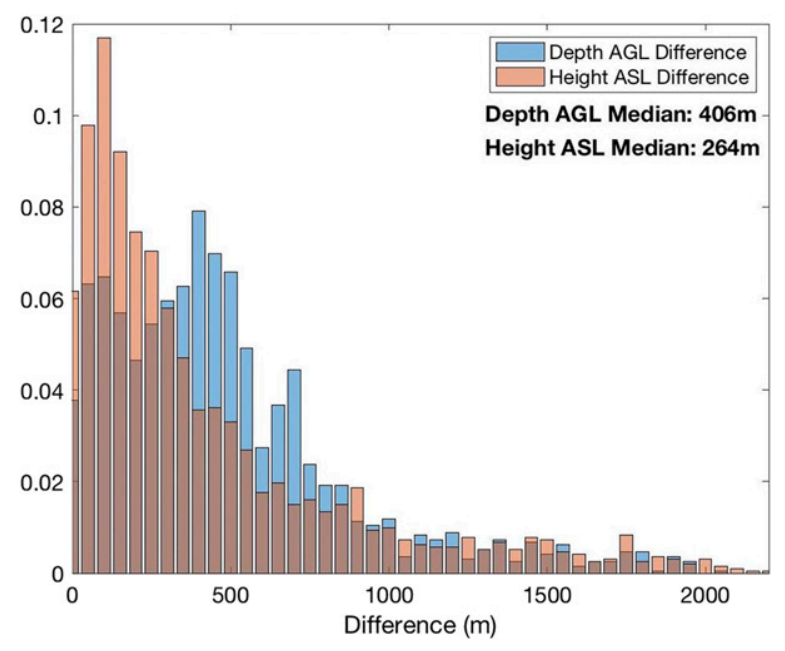

FIG. 16. Histograms of the differences in height of the cold pool tops above sea level (red) and as depth above ground level (blue) for all pairs of observations during all cold pool events identified throughout WFIP2, as shown in Fig. 10.

pool than previous studies have used due to limited instrumentation. This algorithm could be applied to other locations with specifications based on the wind direction and depth of the cold pool since these depend on the topography (direction of the mountain range and height of basin). This instrument set allowed for both a more detailed look at individual cold pool events and a broader look at the characteristics of events over two winters. Statistics built upon all identified cold pool cases show easterly winds occur only occasionally outside of wintertime cold pool events. Although the wind speeds within the cold pool are slower than noncold pool conditions, above the cold pool, the wind speeds tend to be faster, resulting in larger wind speed gradients. However, the directional shear of the horizontal wind with height is not as drastic as the wind speed shear, and the wind directions above the cold pools are predominantly southwesterly. Cold pools have strongly stable temperature gradients, often greater than $10^{\circ} \mathrm{C} \mathrm{km}^{-1}$, between the surface measurements and $1000 \mathrm{~m} \mathrm{AGL}$. The cold pool top, measured by the peak in the wind vector gradient, is observed to be flat MSL throughout the basin, with average heights over all sites of 1100-1200 m MSL. The cold pool top is clearly observed as the cold pool top descends (at rates that vary by event), when high wind speeds approach the wind-turbine layer and wind ramps occur. With a better understanding of the structure and behavior of cold pools, numerical forecast models can be improved to better capture the timing of the descent of the cold pool top boundary that leads to strong increases in wind speeds (Olson et al. 2019). Improved forecasts of wind ramps will allow for a more accurately balanced electrical grid, with less curtailment and overall lower costs of electricity with increased amounts of renewable sources.

Acknowledgments. We are grateful to the individuals who aided in the site selection, leases, instrument deployment and maintenance, data collection, and data QC, including Clark King, Jesse Leach, Tom Ayers, Daniel Wolfe, Timothy Coleman, Daniel Gottas, Scott Abbott, Randy Nishiyama, and Irina Djalalova from NOAA/ESRL/PSD, Richard Eckman and Kirk Clawson from NOAA/ARL, Andy Clifton and Jennifer Newman formerly of DOE/NREL, and David Cook and Richard Coulter from DOE/ANL. We thank Allen White of NOAA/ESRL/PSD for the site map in Fig. 2. All WFIP2 data are available on the DOE Data Archive and Portal at https://a2e.energy.gov/data\#wfip2. Funding for this work was provided by the DOE, Office of Energy Efficiency and Renewable Energy, Wind Energy Technologies Office, and by the NOAA/ESRL Atmospheric Science for Renewable Energy program. We also would like to thank the three reviewers for their time and expertise shared to improve this manuscript.

\section{REFERENCES}

Bianco, L., and J. M. Wilczak, 2002: Convective boundary layer depth: Improved measurement by Doppler radar wind profiler using fuzzy logic methods. J. Atmos. Oceanic Technol., 19, 1745-1758, https://doi.org/10.1175/1520-0426(2002)019<1745:CBLDIM> 2.0.CO;2.

- I. V. Djalalova, J. M. Wilczak, J. Cline, S. Calvert, E. Konopleva-Akish, C. Finley, and J. Freedman, 2016: A wind energy ramp tool and metric for measuring the skill of numerical weather prediction models. Wea. Forecasting, 31, 1137-1156, https://doi.org/10.1175/WAF-D-15-0144.1.

— K. Friedrich, J. M. Wilczak, D. Hazen, D. Wolfe, R. Delgado, S. P. Oncley, and J. K. Lundquist, 2017: Assessing the accuracy of microwave radiometers and radio acoustic sounding systems for wind energy applications. Atmos. Meas. Tech., 10, 1707-1721, https://doi.org/10.5194/amt-10-1707-2017.

Billings, B. J., V. Grubišić, and R. D. Borys, 2006: Maintenance of a mountain valley cold pool: A numerical study. Mon. Wea. Rev., 134, 2266-2278, https://doi.org/10.1175/MWR3180.1.

Bonneville Power Administration, 2018: Wind Generation \& Total Load in the BPA Balancing Authority. Accessed 22 June 2018, https://ransmission.bpa.gov/business/operations/wind/.

Bossavy, A., R. Girard, and G. Kariniotakis, 2013: Forecasting ramps of wind power production with numerical weather prediction ensembles. Wind Energy, 16, 51-63, https://doi.org/ 10.1002/we.526.

Chachere, C. N., and Z. Pu, 2016: Connections between cold air pools and mountain valley fog events in Salt Lake City. Pure Appl. Geophys., 173, 3187-3196, https://doi.org/10.1007/s00024-016-1316-x.

Chemel, C., G. Arduini, C. Staquet, Y. Largeron, D. Legain, D. Tzanos, and A. Paci, 2016: Valley heat deficit as a bulk measure of wintertime particulate air pollution in the Arve River Valley. Atmos. Environ., 128, 208-215, https:/doi.org/ 10.1016/j.atmosenv.2015.12.058. 
Crosman, E. T., and J. D. Horel, 2017: Large-eddy simulations of a Salt Lake Valley cold-air pool. Atmos. Res., 193, 10-25, https:// doi.org/10.1016/j.atmosres.2017.04.010.

Fernando, H., and J. Weil, 2010: Whither the stable boundary layer? A shift in the research agenda. Bull. Amer. Meteor. Soc., 91, 1475-1484, https://doi.org/10.1175/2010BAMS2770.1.

Francis, N., 2008: Predicting sudden changes in wind power generation. North Amer. Windpower, 5 (9), 58-60.

Friedrich, K., J. K. Lundquist, M. Aitken, E. A. Kalina, and R. F. Marshall, 2012: Stability and turbulence in the atmospheric boundary layer: A comparison of remote sensing and tower observations. Geophys. Res. Lett., 39, L03801, https://doi.org/ 10.1029/2011GL050413.

Grant, L. D., and S. C. van den Heever, 2016: Cold pool dissipation. J. Geophys. Res., 121, 1138-1155, https://doi.org/ 10.1002/2015JD023813.

Greaves, B., J. Collins, J. Parkes, and A. Tindal, 2009: Temporal forecast uncertainty for ramp events. Wind Eng., 33, 309-319, https://doi.org/10.1260/030952409789685681.

International Electrotechnical Commission, 2005: Wind turbinespart 12-1: Power performance measurements of electricity producing wind turbines. IEC 61400-12-1, $96 \mathrm{pp}$.

Lareau, N. P., 2014: The dynamics of persistent cold-air pool breakup. Ph.D. dissertation, Dept. of Atmospheric Sciences, University of Utah, $126 \mathrm{pp}$.

— of a persistent cold-air pool. Bound.-Layer Meteor., 154, 291316, https://doi.org/10.1007/s10546-014-9968-5.

$\longrightarrow$, and — 2015b: Turbulent erosion of persistent cold-air pools: Numerical simulations. J. Atmos. Sci., 72, 1409-1427, https://doi.org/10.1175/JAS-D-14-0173.1.

—, E. Crosman, C. D. Whiteman, J. D. Horel, S. W. Hoch, W. O. Brown, and T. W. Horst, 2013: The persistent cold-air pool study. Bull. Amer. Meteor. Soc., 94, 51-63, https://doi.org/10.1175/ BAMS-D-11-00255.1.

Löhnert, U., D. Turner, and S. Crewell, 2009: Ground-based temperature and humidity profiling using spectral infrared and microwave observations. Part I: Simulated retrieval performance in clear-sky conditions. J. Appl. Meteor. Climatol., 48, 1017-1032, https://doi.org/10.1175/2008JAMC2060.1.

Miró, J. R., J. C. Peña, N. Pepin, A. Sairouni, and M. Aran, 2018: Key features of cold-air pool episodes in the northeast of the Iberian Peninsula (Cerdanya, Eastern Pyrenees). Int. J. Climatol., 38, 1105-1115, https://doi.org/10.1002/joc.5236.

Olofson, K. F. G., P. U. Andersson, M. Hallquist, E. Ljungström, L. Tang, D. Chen, and J. B. Pettersson, 2009: Urban aerosol evolution and particle formation during wintertime temperature inversions. Atmos. Environ., 43, 340-346, https://doi.org/ 10.1016/j.atmosenv.2008.09.080.

Olson, J. B., and Coauthors, 2019: Improving wind energy forecasting through numerical weather prediction model development. Bull. Amer. Meteor. Soc., https://doi.org/10.1175/ BAMS-D-18-0040.1, in press.

Pagès, M., N. Pepin, and J. Miró, 2017: Measurement and modelling of temperature cold pools in the Cerdanya valley (Pyrenees), Spain. Meteor. Appl., 24, 290-302, https://doi.org/ 10.1002/met.1630.

Petkovšek, Z., 1992: Turbulent dissipation of cold air lake in a basin. Meteor. Atmos. Phys., 47, 237-245, https://doi.org/10.1007/ BF01025620.

Pichugina, Y., and Coauthors, 2019: Spatial variability of winds and HRRR-NCEP model error statistics at three Doppler-lidar sites in the wind-energy generation region of the Columbia
River Basin. J. Appl. Meteor. Climatol., 58, 1633-1656, https:// doi.org/10.1175/JAMC-D-18-0244.1.

Reeves, H. D., and D. J. Stensrud, 2009: Synoptic-scale flow and valley cold pool evolution in the western United States. Wea. Forecasting, 24, 1625-1643, https://doi.org/10.1175/2009WAF2222234.1.

Rosenkranz, P. W., 1998: Water vapor microwave continuum absorption: A comparison of measurements and models. Radio Sci., 33, 919-928, https://doi.org/10.1029/98RS01182.

Sauberer, F., and I. Dirmhirn, 1954: Über die Entstehung der extremen Temperaturminima in der Doline Gstettner-Alm (On the occurrence of extreme temperature minimums in the Gstettner-Alm Doline). Arch. Meteor. Geophys. Bioklimatol., 5B, 307-326, https://doi.org/10.1007/BF02242757.

Shaw, W., and Coauthors, 2019: The Second Wind Forecast Improvement Project (WFIP 2): General overview. Bull. Amer. Meteor. Soc., 100, 1687-1699, https://doi.org/10.1175/BAMSD-18-0036.1.

Silcox, G. D., K. E. Kelly, E. T. Crosman, C. D. Whiteman, and B. L. Allen, 2012: Wintertime $\mathrm{PM}_{2.5}$ concentrations during persistent, multi-day cold-air pools in a mountain valley. Atmos. Environ., 46, 17-24, https://doi.org/10.1016/j.atmosenv.2011.10.041.

Smith, R., and Coauthors, 1997: Local and remote effects of mountains on weather: Research needs and opportunities. Bull. Amer. Meteor. Soc., 78, 877-892, https://doi.org/10.1175/ 1520-0477-78.5.853.

Solheim, F., J. Godwin, and R. Ware, 1998a: Passive ground-based remote sensing of atmospheric temperature, water vapor, and cloud liquid water profiles by a frequency synthesized microwave radiometer. Meteor. Z., 7, 370-376, https://doi.org/ 10.1127/metz/7/1998/370.

_ J. R. Godwin, E. Westwater, Y. Han, S. J. Keihm, K. Marsh, and R. Ware, 1998b: Radiometric profiling of temperature, water vapor and cloud liquid water using various inversion methods. Radio Sci., 33, 393-404, https://doi.org/10.1029/ 97RS03656.

Vitasse, Y., G. Klein, J. W. Kirchner, and M. Rebetez, 2017: Intensity, frequency and spatial configuration of winter temperature inversions in the closed La Brevine valley, Switzerland. Theor. Appl. Climatol., 130, 1073-1083, https:// doi.org/10.1007/s00704-016-1944-1.

Vrhovec, T., 1991: A cold air lake formation in a basin-A simulation with a mesoscale numerical model. Meteor. Atmos. Phys., 46, 91-99, https://doi.org/10.1007/BF01026626.

Ware, R., R. Carpenter, J. Güldner, J. Liljegren, T. Nehrkorn, F. Solheim, and F. Vandenberghe, 2003: A multichannel radiometric profiler of temperature, humidity, and cloud liquid. Radio Sci., 38, 8079, https://doi.org/10.1029/2002RS002856.

Whiteman, C. D., X. Bian, and S. Zhong, 1999: Wintertime evolution of the temperature inversion in the Colorado Plateau Basin. J. Appl. Meteor., 38, 1103-1117, https://doi.org/10.1175/ 1520-0450(1999)038<1103:WEOTTI >2.0.CO;2.

—- S. Zhong, W. J. Shaw, J. M. Hubbe, X. Bian, and J. Mittelstadt, 2001: Cold pools in the Columbia Basin. Wea. Forecasting, 16, 432-447, https://doi.org/10.1175/15200434(2001)016<0432:CPITCB > 2.0.CO;2.

_, S. W. Hoch, J. D. Horel, and A. Charland, 2014: Relationship between particulate air pollution and meteorological variables in Utah's Salt Lake Valley. Atmos. Environ., 94, 742-753, https://doi.org/10.1016/j.atmosenv.2014.06.012.

Wilczak, J. M., and Coauthors, 2019: The Second Wind Forecast Improvement Project (WFIP2): Observational field campaign. Bull. Amer. Meteor. Soc., 100, 1701-1723, https://doi.org/ 10.1175/BAMS-D-18-0035.1. 
Wolyn, P. G., and T. B. McKee, 1989: Deep stable layers in the intermountain western United States. Mon. Wea. Rev., 117, 461-472, https://doi.org/10.1175/1520-0493(1989)117<0461:DSLITI> 2.0.CO;2.

Yu, L., S. Zhong, and X. Bian, 2017: Multi-day valley cold-air pools in the western united states as derived from NARR. Int J. Climatol., 37, 2466-2476, https://doi.org/10.1002/joc.4858.

Zängl, G., 2003: The impact of upstream blocking, drainage flow and the geostrophic pressure gradient on the persistence of cold-air pools. Quart. J. Roy. Meteor. Soc., 129, 117-137, https:// doi.org/10.1256/qj.02.99.
Zhong, S., C. D. Whiteman, X. Bian, W. J. Shaw, and J. M. Hubbe, 2001: Meteorological processes affecting the evolution of a wintertime cold air pool in the Columbia Basin. Mon. Wea. Rev., 129, 2600-2613, https://doi.org/10.1175/15200493(2001)129<2600:MPATEO > 2.0.CO;2.

X. Bian, and C. D. Whiteman, 2003: Time scale for cold-air pool breakup by turbulent erosion. Meteor. Z., 12, 229-233, https://doi.org/10.1127/0941-2948/2003/0012-0231.

— - X. Xu, X. Bian, and W. Lu, 2011: Climatology of persistent deep stable layers in Utah's Salt Lake Valley, USA. Adv. Sci. Res., 6, 59-62, https://doi.org/10.5194/asr-6-59-2011. 